\title{
Ecological Drawbacks of Nanomaterials Produced on an Industrial Scale: Collateral Effect on Human and Environmental Health
}

\author{
H. Pérez-Hernández • A. Pérez-Moreno · C. R. Sarabia-Castillo • \\ S. García-Mayagoitia • G. Medina-Pérez $\cdot$ F. López-Valdez $\cdot$ \\ R. G. Campos-Montiel · P. Jayanta-Kumar · F. Fernández-Luqueño
}

Received: 5 April 2021 / Accepted: 28 September 2021 /Published online: 12 October 2021

(C) The Author(s), under exclusive licence to Springer Nature Switzerland AG 2021

\begin{abstract}
Currently, hundreds of different nanomaterials with a broad application in products that make daily lives a little bit easier, in every aspect, are being produced on an industrial scale at thousands of tons per year. However, several scientists, researchers, politics, and ordinary citizens have stated their concern regarding the life cycle, collateral effects, and final disposal of these cutting-edge materials. This review summarizes, describes, and discusses all manuscripts published in the Journal Citation
\end{abstract}

H. Pérez-Hernández

El Colegio de la Frontera Sur, Agroecología, Unidad

Campeche, 24500 Campeche, Mexico

e-mail: hermes.perez@estudianteposgrado.ecosur.mx

A. Pérez-Moreno - C. R. Sarabia-Castillo .

S. García-Mayagoitia $\cdot$ F. Fernández-Luqueño $(\bowtie)$

Sustainability of Natural Resources and Energy Programs,

Cinvestav-Saltillo, 25900 Coahuila, Mexico

e-mail: cinves.cp.cha.luqueno@gmail.com

C. R. Sarabia-Castillo

e-mail: cesar.sarabia@cinvestav.edu.mx

S. García-Mayagoitia

e-mail: selvia.garcia@cinvestav.edu.mx

G. Medina-Pérez · R. G. Campos-Montiel Instituto de Ciencias Agropecuarias, Universidad

Autónoma del Estado de Hidalgo, Tulancingo,
Reports during the last 10 years, which studied the toxicity or the effects of nanomaterials on human and environmental health. It was observed that $23.62 \%$ of the manuscripts analyzed found no ecological or human risks; $54.39 \%$ showed that several nanomaterials have toxicological effects on the ecosystems, human, or environmental health. In comparison, only $21.97 \%$ stated the nanomaterials had a beneficial impact on those. Although only $54.39 \%$ of the manuscripts reported unfavorable effects of nanomaterials on ecosystems, human, or environmental health, it is relevant because the potential damage is invaluable. Therefore, it is imperative to make toxicological studies of nanomaterials with holistic

Hidalgo, C. P. 43000, México

e-mail: gamepe@yahoo.com

R. G. Campos-Montiel

e-mail: rcampos@uaeh.edu.mx

F. López-Valdez

Agricultural Biotechnology Group, Research Center for Applied Biotechnology (CIBA), Instituto Politécnico

Nacional, 90700 Tlaxcala, Mexico

e-mail: flopez2072@yahoo.com

P. Jayanta-Kumar

Research Institute of Biotechnology \& Medical Converged

Science, Dongguk University-Seoul, Goyang 10326,

Republic of Korea

e-mail: jkpatra.cet@gmail.com 
focus under strictly controlled real conditions before their commercialization, to deliver to the market only innocuous and environmentally friendly products.

Keywords Ecofriendly · Ecological risks · Environmental pollution - Green synthesis . Nanoparticle $\cdot$ Nanotechnology and nanoscience . Nanotoxicology $\cdot$ Social welfare $\cdot$ Soil degradation . Sustainable development

\section{Introduction}

Engineered nanomaterials (ENMs) have been synthesized by different procedures, which confer particular and exceptional properties never seen before. Therefore, these nanosized materials' production has moved from the laboratories to the industrial sector, where thousands of tons are produced annually. ENMs have been characterized by their capacity to improve the transport and delivery of drugs, fertilizers, enzymes, and genetic material, among others. Besides, ENMs have also been a breaking point regarding technological areas such as electronics, medicine, high-performance computing, chemical engineering, and agriculture (Medina-Pérez et al., 2020; Fernández-Luqueño, 2019; Pérez-Hernández et al., 2020). It is well known the benefit that nanoscience and nanotechnology have brought to society regarding the advances that these cutting-edge knowledge areas. If it were not enough, these advantages would increase dramatically in a short period. However, hitherto the studies regarding the effects of ENMs on human and environmental health, their toxicity, and drawbacks have been scarcely reported (Pérez-Hernández et al., 2020).

Currently, the price of ENMs has decreased over time, and the productivity expanded to several thousand tons per year for technological applications. This production and market behavior have been reported before for single- or multi-walled carbon nanotubes (SWCNTs or MWCNTs, respectively) (Zhang et al., 2013). Besides, Piccinno et al. (2012) stated that the ENM production at the industrial scale had reached almost 80,000 tons during 2011.

The undesirable effects of ENMs produced on an industrial scale on human health, ecology, and environment have been discussed by Shakeel et al. (2017), Ivask et al. (2014), Bondarenko et al. (2013), Ma et al.
(2013), Cao and Luo (2019), Du et al. (2013), and Line et al. (2017). It has been stated that $\mathrm{TiO}_{2}$ nanoparticles $\left(\mathrm{TiO}_{2}\right.$-NPs) enter through the pulmonary route and translocate to the brain or the systemic circulation from where these reached the kidney, liver, etc. (Shakeel et al., 2017). According to the same authors, $\mathrm{TiO}_{2}$-NPs generate reactive oxygen species (ROS), histopathological alterations, carcinogenesis, genotoxicity, and immune disruption. A comprehensive and critical literature overview on factors modifying the toxic effect of NPs and their toxicity mechanisms of ENMs on various environmentally relevant test species was addressed by Ivask et al. (2014) and Bondarenko (2013). High acute toxicity of ZnO-NPs to bacteria, algae and plants, aquatic and terrestrial invertebrates, and vertebrates was described by $\mathrm{Ma}$ et al. (2013). This toxicity was highly dependent on test species, physicochemical properties of the ENMs, and test procedures. In contrast, particle dissolution and particle-induced generation of ROS represented the principal modes of action for NPs toxicity through all species evaluated by Ma et al. (2013).

According to Cao and Luo (2019), carbon nanotubes (CNTs) might induce adverse vascular effects in laboratory animals. Simultaneously, only limited reports have been obtained from CNT-exposed human beings, and their results are inconclusive. The potential risks regarding CNTs and harmful effects resulting from exposure of animals, microorganisms, and crops to CNTs, also stated by Du et al. (2013), through in vitro and in vivo tests. Besides, CNTs' impact on the terrestrial ecosystem, their behavior in soil and plants, interactions with other pollutants, and their implications on soil organisms and plants were studied by Pérez-Hernández et al. (2020) and Line et al. (2017). Therefore, ENMs must be either avoided or strictly managed to minimize risks for human and environmental health. Besides, there is increasing evidence that ENMs threaten non-target organisms.

It is hypothesized that ENMs produced on an industrial scale have several drawbacks that jeopardize human and environmental health. However, these threats are not widely recognized because most published studies have been carried out in a laboratory under controlled conditions. Therefore, longterm in situ field trials are required to understand and dimensive the magnitude of the problem that we could face up in a short period. 
This review aims to discuss the manuscripts published in the Journal Citation Reports during the last 10 years, which studied the ecological toxicity, the drawbacks, and the effects of ENM produced on an industrial scale on human and environmental health.

\section{Materials and Methods}

\subsection{Search Strategy, Information Resources, and Inclusion Criteria}

This systematic review exhaustively covers all studies published online and limited to English between 2012 and 2021 years (the last search was run on 15 August 2021) following the methodology PRISMA (Preferred Reporting Items for Systematic Reviews and Meta-Analyses). Even though this review discusses the positive effects of ENMs such as $\mathrm{TiO}_{2}$, $\mathrm{Ag}, \mathrm{Zn}, \mathrm{Si}, \mathrm{Fe}, \mathrm{Al}, \mathrm{Ce}$, and CNTs, it emphasizes their toxicity on edible and inedible plants and soil organisms. Therefore, search restrictions in the period 2012-2021, is due to two criteria: (1) based to most widely ENMs produced annually and used worldwide, and (2) to the fact that in the last ten years, several articles that address the toxicological effect of the properties of ENMs. These effects have been discussed regarding organisms (plants, soil organisms, and humans), within which the adverse effects were related to several features of NPs, such as size, shape, exposure time, or concentration. Besides, the investigations carried out during the last years have used cutting-edge techniques for detection, measurement, or synthesis, which have helped to understand these phenomena. It even has opened new knowledge areas related to toxicity in plants or soil biota at the level of cellular damage, proteins, DNA, and enzymes, among others. Into the bargain, new researches that address the issues of biotransformation of ENMs in the food chain and possibly collateral effects on humans have appeared.

The literature search strategy was carried out using the "Web Science" database. The search was based on a pre-determined series of keywords in title and topic such as "nano," "nanomaterials," "nanoparticles," “organisms," "soil invertebrate," "macroinvertebrate soil," "soil macrofauna," "soil mesofauna," "earthworms," "terrestrial isopods," "collembola," "symbiotic interaction ships," "mycorrhizal fungi", "plants edible," "plants inedible," and "trophic chain." Boolean operators "AND" and "OR" were used as search parameters to expand the search. Also, we used the wildcard (*), which allows and includes all the keywords that start with the preceding characters.

The studies consulted were mainly based on those that evaluated the effects of the ENMs (positive, negative, or null) of $\mathrm{TiO}_{2}, \mathrm{Ag}, \mathrm{Zn}, \mathrm{Si}, \mathrm{Fe}, \mathrm{Al}, \mathrm{Ce}$, and CNT. It is important to note that, although studies report heterogeneous statistical analyzes, we intend to demonstrate the effects (mostly adverse) regardless of the evaluation time and status of growth and development of plants and soil organisms. Therefore, data were included if the studies met the following criteria: (1) the studies reported positive, negative, or null effects on morphological and chemical characteristics in plants, mesofauna, macrofauna, and arbuscular mycorrhizal fungi; (2) investigations that in their methodology specified factors such as evaluated concentration, size of NMs, and study time; and (3) studies conducted in the laboratory, greenhouse, and field (agar culture media, artificial soil, natural soil, and hydroponics). On the other hand, we exclude the reports that evaluated or used ENMs different from those of our interest (Fig. 1).

Two reviewers were responsible for the selection of articles. Individually, each of the selected articles was reviewed in the summaries, results, and conclusions. On the other hand, five reviewers wrote the results and discussion sections. At the same time, from the studies selected and considered for the results sections, we developed a summary of data presented in graphs. Minitab software (Version 18) was used to draw the figures.

\section{Results and Discussion}

\subsection{Nanomaterials Produced on an Industrial Scale}

The rapid development in NPs production technologies and the increasing application of ENMs in daily products have increased the number of registered nanoproducts. It had augmented from 54 in 2005 to 1865 in 2013 and more than 3000 in 2020 . With this 
Fig. 1 Flow diagram of study selection (according to criteria of PRISMA)

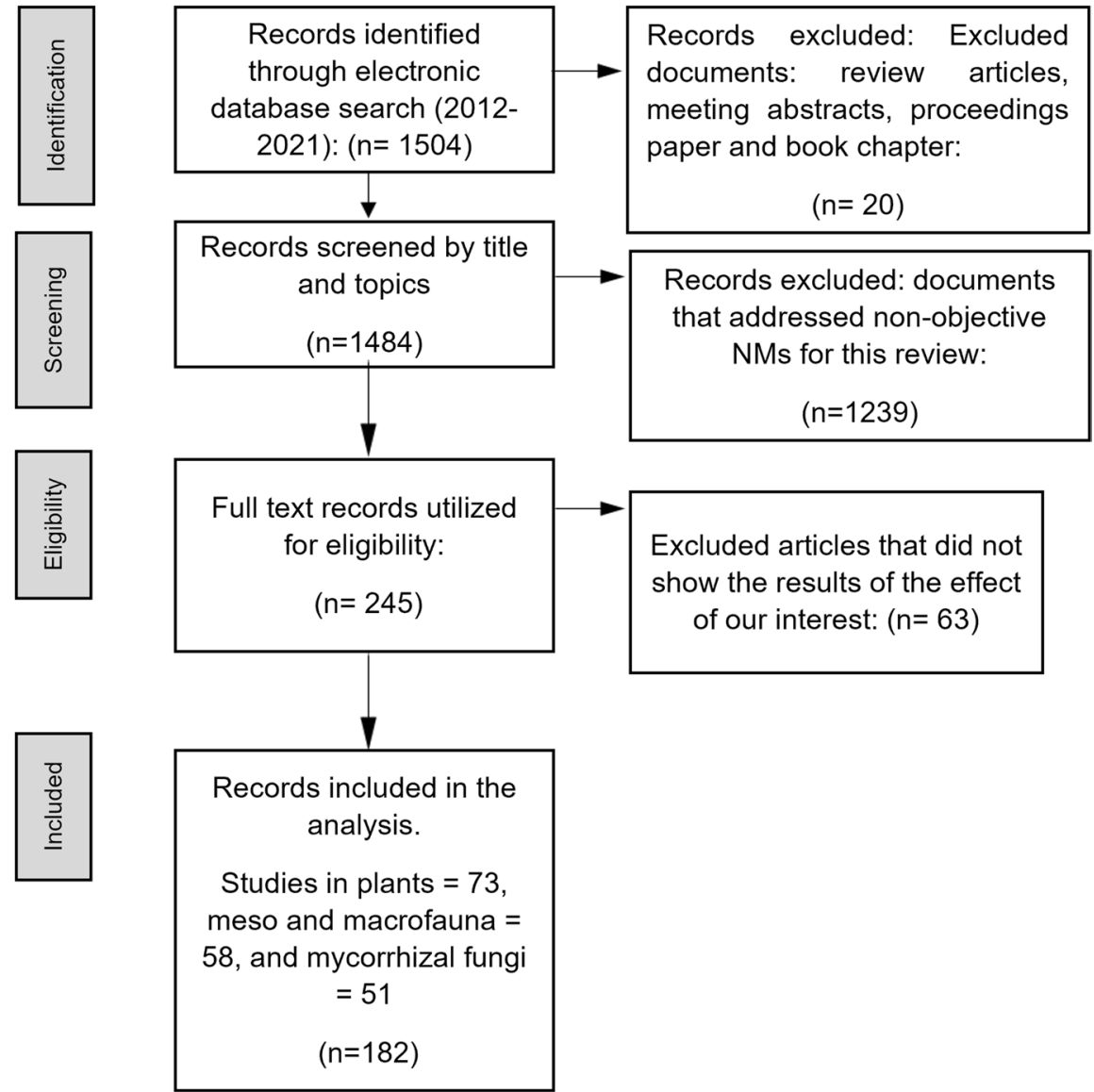

approach, massive developments in various application areas are predicted (Rai et al., 2012).

ENMs are being more common in daily used products. According to the Global Industry Analysts' 2010 report, the global market for nanomaterials (NMs) reached around US\$ 6.2 million by 2015 . The market of cosmetics, medicine, agriculture, food, food packaging, electronics, paints, medical devices, and coatings are some examples of the widespread use of ENMs (Pine et al., 2007).

A method that has been employed in NPs production is the continuous-flow hydrothermal synthesis (CFHS), in which a hot stream of deionized water and a cold stream of a precursor mixed with deionized water meet in the reactor to form NPs. These temperatures usually range between 250 and $400{ }^{\circ} \mathrm{C}$. Some of the precursors used in this kind of process are titanium oxysulfate (TiOS) for $\mathrm{TiO}_{2}$ and zinc nitrate $\left(\mathrm{Zn}\left(\mathrm{NO}_{3}\right)_{2}\right)$ for $\mathrm{ZnO}$. The NPs are obtained after the post-processing method of washing the concentrated solution. After that, the material is sedimented, obtaining the NPs concentrated (Rai et al., 2012).

Wet methods generally perform better in terms of quality, and the NPs are better suited for specialized applications than those produced by dry processes. The batch hydrothermal and solvothermal methods produce NPs suitable for the electrical industry as semiconductor materials $(\mathrm{ZnO})$. In $\mathrm{TiO}_{2}$, its particle size, provided by wet technologies, varies from 10 to $20 \mathrm{~nm}$. The CFHS is a wet method, which produces NPs with the highest quality. By the combustion synthesis, very small and non-agglomerated NPs are produced (Stieberova et al., 2019).

Some methods have the highest $\mathrm{TiO}_{2}$ production rates, where vapor-assisted flame pyrolysis (VAFP) is included. The first one is the Altair method, which is a chloride process with a production rate for fine metal powders of up to $25,000 \mathrm{kgh}^{-1}$. The second one is the sulfate process, with a production rate of $100 \mathrm{kgh}^{-1}$ (Rai et al., 2012). These methods are not versatile; the 
VAFP method is applicable only for $\mathrm{TiO}_{2}$, obtaining NPs with a diameter of $200 \mathrm{~nm}$ for use in pigments, $\mathrm{SiO}_{2}$, and other simple oxides. The sulfate process is appropriate only for $\mathrm{TiO}_{2}$. A high-temperature plasma (HT plasma) high production rate can be estimated at up to $60 \mathrm{kgh}^{-1}$ at $400 \mathrm{~kW}$. The production rate from the typical HT plasma plant is lower than $10 \mathrm{~kg} \mathrm{~h}^{-1}$. Another method is the continuous-flow hydrothermal synthesis (CFHS), with an average production rate of $10 \mathrm{~kg} \mathrm{~h}^{-1}$. It is one of the highest productive ways to produce large volumes of NPs demanded commercial applications (Stieberova et al., 2019).

$\mathrm{TiO}_{2}$-NPs are used as semiconductors in the fields of energy due to their property of absorbing ultraviolet (UV) light at wavelengths shorter than their bandgap (3.2 eV for anatase), triggering photocatalytic activities (Fu et al., 2015). Also, $\mathrm{TiO}_{2}$-NPs are used in commercial products such as solar cells, sunscreens, self-cleaning surface coatings, disinfectant sprays, and water treatment agents (Katal et al., 2020; Chung $\&$ Wang, 2012). The $\mathrm{TiO}_{2}$-NPs are low-cost materials, have high photocatalytic activity, considerable photostability, and non-toxicity. $\mathrm{TiO}_{2}$-NPs are classified into three main crystal structures, such as anatase (stable at low temperature), brookite (found in minerals with an orthorhombic crystal structure), and rutile (stable at higher temperatures) (Kunhikrishnan et al., 2015).

There are some methods and leading strategies for the synthesis of faceted $\mathrm{TiO}_{2}$ crystals. These could be classified as the wet-chemistry route (hydrothermal, solvothermal, and nonhydrolytic), gas oxidation route, crystallization transformation from amorphous $\mathrm{TiO}_{2}$, epitaxial growth, and spray-drying (Chung \& Wang, 2012). The low-temperature plasma (LT plasma) is used to produce NPs for highly specialized products (Stieberova et al., 2019). The Altair hydrochloride process produces anatase $\mathrm{TiO}_{2}$-NPs with an average diameter of $40 \mathrm{~nm}$ (Grubb \& Bakshi, 2010). The size for NPs produced by HT plasma ranges from 50 to $100 \mathrm{~nm}$.

$\mathrm{TiO}_{2}$ is the most popular semiconductor photocatalyst, but recently other ENPs have attracted much attention due to its admirable attributes, such as $\mathrm{ZnO}$. It is a multifunctional material that has unique physical and chemical properties. It also is a no-toxic, lowcost ENM and can be synthesized easily and suitable for mass production. The nanostructured $\mathrm{ZnO}$ is a chemoresistive sensing material; it react with the adsorbed oxygen species present on the surface of the material containing target gas molecules such as $\mathrm{CO}$, $\mathrm{NO}_{2}, \mathrm{NO}$, ethanol, $\mathrm{H}_{2} \mathrm{~S}, \mathrm{H}_{2}$, acetone, acetaldehyde, LPG, and $\mathrm{NH}_{3} \mathrm{HCHO}$, altering the electric conductance (Grubb \& Bakshi, 2010; Caramazana-González et al., 2017; Yu et al., 2016).

$\mathrm{ZnO}-\mathrm{NPs}$ are an essential material in the ceramics industry because of their hardness, rigidity, and piezoelectric constant. Simultaneously, its low toxicity, high biocompatibility, and tested biodegradability make it an ENM of interest for biomedicine and in pro-ecological systems (Zhu \& Zeng, 2017). Different processes are adopted to synthesize the $\mathrm{ZnO}-\mathrm{ENM}$, such as conventional solid-state reaction, hydrothermal, sol-gel, chemical co-precipitation, microwave, and emulsion method. Most of these techniques are time-consuming and not cost-effective because of high-temperature processing and expensive equipment. Emerging low-temperature technology is the solution combustion synthesis (SCS); it is a facile and economically feasible technique.

In the literature, it is mentioned that there are not only the chemical methods for the production of $\mathrm{ZnO}$, as the ones above, there also exist metallurgical processes, where de NPs are obtained by roasting suitable zinc ore via a direct or indirect method. The straightforward process involves reducing the zinc ore by heating with coal, followed by the oxidation of zinc vapor in the same reactor in a single production cycle (Zhu \& Zeng, 2017). The long process is where the metallic zinc is melted in a furnace and vaporized at $910{ }^{\circ} \mathrm{C}$. The immediate reaction of the zinc vapor with oxygen from the air produces $\mathrm{ZnO}$. It has to be stated that crystalline oxide powders, combined with other materials, provide the possibility to obtain improved chemical, mechanical, optical, or electrical properties (Zhu \& Zeng, 2017).

Silica nanoparticles have excellent optical, electrical, and thermal properties and features as easy preparation, well-defined dimensions, making it a suitable material for many applications. In industries, $\mathrm{SiO}_{2}$ is used in catalysis, pigments, electronic devices, thermal insulators, humidity sensors, etc. In pharmaceuticals, it is used in enzyme encapsulation, drug delivery, cell markers, etc. (Manjunath et al., 2020).

In the concrete industry, the market demand for cement, concrete's binder, keeps growing every year. The annual production of cement increased from 3.6 billion tons to 4.1 billion tons worldwide, from 2011 
to 2015. Nonetheless, cement manufacture is responsible for $5-7 \%$ of global anthropogenic $\mathrm{CO}_{2}$ emissions. There has been implemented the reduction of usage of cement and make concrete more sustainable construction material. Some advances in replacing ordinary Portland cement (OPC) with supplementary cementitious materials (SCMs) are promising alternatives. Some common SCMs are often much less reactive than the clinkers of OPC, resulting in a slow strength development of the mixing concrete. However, some ENMs, such as $\mathrm{SiO}_{2}, \mathrm{TiO}_{2}, \mathrm{Al}_{2} \mathrm{O}_{3}, \mathrm{CNT}$, graphene, and others, are often used to compensate for this drawback presenting excellent performances in terms of the early age strength gain (Wang \& Park, 2015; Antiohos et al., 2014). Somewhere else, it was reported that the compressive strength of mortar with $\mathrm{SiO}_{2}$ particles was higher than those of mortars containing silica fume at 7 and 28 days; $\mathrm{SiO}_{2}$ behaves not only as a filler but also as an activator to promote pozzolanic reaction (Feng et al., 2020).

$\mathrm{SiO}_{2}$ has attracted attention as a promising alternative anode material due to its high theoretical capacity $\left(1965 \mathrm{~mA} \mathrm{hg}^{-1}\right)$. Also, it is a commercially viable electrode material for $\mathrm{Li}$-ion batteries for its natural abundance, low cost, and environmental friendliness (LIBS). Nonetheless, it has some limitations in the practical application. The high capacity of $\mathrm{SiO}_{2}$ cannot be fully utilized owing to its poor electronic conductivity. Another problem is its capacity fading caused by volume expansion during cycling (Rai \& Haque, 2014).

Many techniques are used to prepare silica NPs, such as plasma synthesis, chemical vapor deposition (CVD), sol-gel process, and chemical precipitation. The most recommended synthesis of silica nanoparticles is the sol-gel method due to its easy preparation process, the ability to control the particle size, size distribution, and morphology by monitoring the experimental conditions (Manjunath et al., 2020).

Iron and oxygen are two of the four most common elements in Earth's crust, and iron oxides form naturally through the weathering of Fe-containing rocks both on land and in the oceans. Iron oxides are in natural abundance in rocks, soils, and dust and play an essential role in geochemistry. Iron oxides are imperative because these can be used as a source of $\mathrm{Fe}$, which is processed to make steel. Other applications include corrosion protective coatings $\left(\mathrm{Fe}_{3} \mathrm{O}_{4}\right.$ or "black rust") and use in recording media and catalysis. In the biomedicine field, $\mathrm{Fe}_{3} \mathrm{O}_{4}$ nanoparticles are used as a contrast agent in MRI scanners. In hyperthermia treatment, tumors can be killed by the local temperature increase that occurs when $\mathrm{Fe}_{3} \mathrm{O}_{4} \mathrm{NP}$ are placed in a rapidly varying magnetic field (Belgivayeva \& Taniguchi, 2019).

According to the crystallographic phase and the oxygen content, the semiconductor hematite $\alpha-\mathrm{Fe}_{2} \mathrm{O}_{3}$ phase or half-metallic magnetite spinel $\mathrm{Fe}_{3} \mathrm{O}_{4}$ phase can be observed in various optical, electrical, and magnetic properties. The $\alpha-\mathrm{Fe}_{2} \mathrm{O}_{3}$ exhibits weak ferromagnetism, whereas the magnetite is ferrimagnetic at ambient temperature. The $\mathrm{Fe}_{3} \mathrm{O}_{4}$ behaves almost like an electric metallic conductor, while the hematite phase displays electrical insulating property. Hematite is also an anode for a lithium-ion battery or photoelectrochemical water splitting, as a pigment, wastewater treatment, gas sensor, etc. Magnetite is employed in biomedical therapies, magnetic printing, microelectronics as microwave-absorbing materials, thermoelectricity, or a thermistor in a bolometer $(\mathrm{Li}$ \& Zhou, 2019).

There have been developed cathode materials in the supercapacitors area as carbons, used as harmful materials due to their high specific surface area, high power density, and good electrical conductivity. Still, the capacitance value has been restricted by energy density. Transition metal oxides such as $\mathrm{MnO}_{2}, \mathrm{NiO}$, $\mathrm{CuO}, \mathrm{Co}_{2} \mathrm{O}_{3}$, and $\mathrm{FeO}$ exhibit higher specific capacitance and conductivity due to storing charges by highly reversible faradaic redox reaction on the electrode surface.

Another ENP with wide applications is aluminum oxide (AlO), which exists in several crystallographic polymorphs. Thin and thick films of AlO-ENPs are used in microelectronics and catalysis, also as a diffusion barrier, thermal barrier, and water-resistant coatings for cutting tools. Besides, $\gamma$-alumina, which is a metastable phase, is used in catalysis due to its large surface area (Aubry et al., 2019). Also, $\gamma-\mathrm{Al}_{2} \mathrm{O}_{3}$ is considered the most effective adsorbent, not only for its high surface area but even for its enhanced reactivity for adsorption and mass transfer efficiency (Nayar et al., 2014). At the same time, the anodic alumina templates are used for the synthesis of nanowires (Aubry et al., 2019).

Mechanical milling, vapor phase reaction at high temperature, combustion method, sol-gel method, 
and precipitation method are strategies to synthesize AlO-ENP. The sol-gel process has attracted interest due to the morphology and homogeneity, and surface area of the particles can be easily controlled. Sol-gel synthesis of alumina particles comprises hydrolysis of aluminum alkoxide in water to obtain boehmite $(\mathrm{AlOOH})$ as gel and its calcination at $400-800$ to produce $\gamma-\mathrm{Al}_{2} \mathrm{O}_{3}$ (Nayar et al., 2014).

The Bayer method, one of the most popular routes applied for the $\mathrm{Al}_{2} \mathrm{O}_{3}$ manufacture, produces about 45 million tons. Its method uses bauxite, and about 40 million tons are consumed for refining aluminum. Nonetheless, nearly 5 million tons of $\mathrm{Al}_{2} \mathrm{O}_{3}$ are produced for chemical-grade and used for various purposes. The production methods used to create high purity $\alpha-\mathrm{Al}_{2} \mathrm{O}_{3}$, besides the Bayer method (99.6-99.9\% purity), are the hydrolysis of aluminum alkoxides, chemical vapor deposition (CVD), thermal decomposition of aluminum alum, and thermal decomposition of inorganic aluminum salts (Singh et al., 2016).

The $\gamma-\mathrm{Al}_{2} \mathrm{O}_{3}$ is an essential catalyst in the electrochemistry area and is useful as catalyst support in the automotive and petroleum industries. The different synthesis routes developed to prepare organized mesoporous alumina and ordered alumina using surfactant micelles (polyethylene) as a structure-directing agent are explained in the literature. Another path is using ultrasound treatment. With these routes, it has been demonstrated the different structures using the nitrogen physisorption characterization. The ultrasound treatment led to the transformation of inkbottle pores into a cylindrical form, and the surface area and pore size were increased. Aluminas prepared with polyethyleneimine as a template showed larger cylindrical wormhole-like mesopores with a broader pore size distribution, high surface area, and pore volume. It was found that with the ultrasound treatment, the alumina NP demonstrated high catalytic activity and had unusual porous structure and large crystallite size (Vinogradov et al., 2010).

The cerium oxide ENPs (CeO-ENPs) are used in industrial applications such as chemical/polarization polishing, corrosion protection, fuel oxidation catalysts, and the non-industrial section as antibiotics and drug transfer (Shirai et al., 2009). $\mathrm{CeO}_{2}$-ENPs had received more attention due to their useful catalysis applications, fuel cells, and antioxidants in biological systems. Ce exists in two oxidation states: $\mathrm{Ce}^{3+}$ and $\mathrm{Ce}^{4+}$. Therefore, $\mathrm{CeO}_{2}$ can have two different oxide forms, $\mathrm{CeO}_{2}\left(\mathrm{Ce}^{4+}\right)$ or $\mathrm{Ce}_{2} \mathrm{O}_{3}\left(\mathrm{Ce}^{3+}\right.$, in a bulk material). $\mathrm{CeO}_{2}$-ENPs have improved redox properties concerning the bulk materials. $\mathrm{CeO}_{2}$-ENPs are effective against pathologies associated with chronic oxidative stress and inflammation. Besides, they are used for biomedicine in the bioanalysis field and drug delivery due to their reflective properties compared to the multienzyme (Reed et al., 2014). Some biological applications of $\mathrm{CeO}_{2}$-ENPs are the antibacterial effect inhibiting both gram-negative and gram-positive bacteria. They are also useful in the neurodegenerative treatment, in enzyme mimetic forms, catalase, and peroxidase mimicking activity as a catalyst, in sensing applications, and angiogenesis induction (Reed et al., 2014).

There are synthetic methods divided into two regimes: lower temperatures $\left(<250{ }^{\circ} \mathrm{C}\right)$ and higher temperatures extended to combustion, flame synthesis, and even plasma arc temperature, reaching several thousand degrees centigrade. The most commonly employed lower temperature wet-chemical synthetic methods are co-precipitation, hydrothermal, solvothermal, sol-gel, Pechini, microemulsion, and reversed micelle methods. These synthetic methods are useful for small-scale and research quantities of materials (Miri et al., 2019).

Calcination is commonly used as a high-temperature technique for the industrial-scale production of ceria. This process involves high treatment below the melting point of the material in an oxygen atmosphere. Some industrial firms have patented their methods, including Hitachi with the precipitation of ENPs, using carbonate chemistry prominent, then calcined, and milled; Rhodia technique with precipitation using hydroxide chemistry noticeable after that calcined and milled; Antaria process with precipitation of ENMs while being mechanically milled in $\mathrm{NaCl}$ media; Umicore, precipitation while being evaporated (thermal spray), and Evonik technology using a pyrogenic gas-phase formation from metalalkoxides or metal-carboxylates (Miri et al., 2019).

Also, there exist green approaches for $\mathrm{CeO}_{2}$-ENPs synthesis. One of them is plant-mediated synthesis, consisting of the phytosynthesis of metal and metal oxide ENPs using plants as Gloriosa superba, Aloe vera, and others. The ENPs obtained shoed smaller crystal sizes with a higher surface area led to higher antibacterial activity. Still, these ENPs were generally 
so large, so they are appropriate for biomedical applications. In the case of the mycosynthesis technology to synthesize $\mathrm{CeO}_{2}$-ENPs, it showed advantages as manageability and cost-effectiveness. This technology was less time-consuming and required less energy and can be used as an economical and valuable alternative for the large-scale production of ENPs. Other mentioned green synthesis is the nutrient-mediated synthesis and the biopolymer-mediated synthesis (Reed et al., 2014).

The commercial interest in carbon nanotubes (CNTs) has been increasing around the world, and it is reflected in the production capacity that presently exceeds several thousand tons per year. Bulk CNT powders are incorporated in various commercial products ranging from rechargeable batteries, automotive parts, and sporting goods to boat hulls and water filters. CNTs are seamless cylinders of one or more graphene layers, denoted as SWCNTs or MWCNTs, with open or closed ends. The best CNTs have all carbons bonded in hexagonal lattice except at their ends. In contrast, defects in mass-produced CNTs introduce pentagons, heptagons, and other imperfections in the sidewalls that generally degrade desired properties. The diameters of SWCNTs are typically 0.8 to $2 \mathrm{~nm}$, and the MWCNTs are about 5 to $20 \mathrm{~nm}$, sometimes could exceed $100 \mathrm{~nm}$. CNTs' lengths range from less than $100 \mathrm{~nm}$ to several centimeters (Charbgoo et al., 2017).

Most CNT production is used in bulk composite materials and thin films, which rely on unorganized CNTs architectures having limited properties. Organized CNT architectures promise to scale up to properties of individual CNTs and realize new functionalities (Charbgoo et al., 2017). One of the methods for CNT synthesis is chemical vapor deposition (CVD). However, large-scale CVD methods yield contaminants that can influence CNT properties (Charbgoo et al., 2017).

The synthesis of long, aligned CNTs that can be processed without dispersion in a liquid offers promise for cost-effective realization of compelling bulk properties. These methods include the self-aligned growth of horizontal and vertical CNTs on substrates coated with catalyst particles and CNT sheets and yarns production directly from floating-catalyst CVD systems. The floating catalyst chemical vapor deposition (FC-CVD) is one method to synthesize CNTs due to its scalability at viable production cost. Its technology is widely used in the industry for continuous production of CNTs with the catalyst ferrocene, stable, non-toxic, and low cost (De Volder et al., 2013).

Some of the applications for MWCNTs are in lithium-ion batteries for notebook computers and mobile phones. It is well known that CNTs increase electrical connectivity and mechanical integrity, which improve rate capability and life cycle. The use of CNTs as a catalyst support in fuel cells can reduce Pt usage by more than 58\% compared to carbon black, and doped CNTs may enable fuel cells that do not require $\mathrm{Pt}$ (Igbokwe et al., 2019).

According to reports, many companies were investing in diverse applications of CNTs, such as transparent conductors, thermal interfaces, antiballistic vests, and wind turbine blades. Further industrial development demands health and safety standards for CNT manufacturing and use. As more substantial quantities of CNT materials reach the consumer market, it will be necessary to establish disposal and use procedures. CNTs may enter municipal waste streams, where, unless they are incinerated, crosscontamination during recycling is possible (Charbgoo et al., 2017).

Metal ENPs have been utilized in fields like drug delivery systems, medical diagnosis, sanitization, and wastewater treatment. Recently different ENPs, in suspension, are in use to induce the catalytic reactions, which have been proved to be the most effective method for treating wastewater. As gold and silver, noble metals are abundantly used in the fields of photography, biological labeling, and catalysis. The high surface area of Ag-ENPs facilitates it to be used as a catalyst in reducing the organic dyes (Maboya et al., 2019). Also, Ag-ENPs have emerged as an attractive alternative approach for antimicrobial and cancer treatments. Nonetheless, their toxicological effects and low biocompatibility limited their clinical applications (Vijayakumar et al., 2020).

In some studies, the Ag-ENPs have demonstrated their toxic effects on bacteria, mammals, animals, cells, and plants. Researchers claim that toxicity to the strong affinity to thiol groups presents in the cells. To decrease the toxicity of these ENPs, they have been biosynthesized using Veronica officinalis extract. These did not exhibit any toxic effects and were spherical and locally agglomerated about $40 \mathrm{~nm}$, affecting their lack of toxicity. However, Ag-ENPs 
stimulated the growth of garden cress, inhibited it, and stimulated it again (Srivastava \& Choubey, 2019).

The methods utilized for Ag-ENPs synthesis are the physical vapor deposition, chemical vapor deposition, sol-gel method, microwave-assisted synthesis, ultra-sonication method, electrochemical synthesis, and chemical reduction of metallic ions. The major disadvantage of using these methods is that the chemicals used in these procedures are costly and toxic, making them hazardous. Another advanced biosynthesis method lately used is bioreduction, in which bacteria, fungi, or plant extracts are used to synthesize nanomaterials. In comparison to all the methods mentioned before, bioreduction is eco-friendly and easy to execute. Also, the Ag-ENPs obtained exhibit more excellent stability utilizing a green synthesis using methanol extract of Citrus limetta peel (Maboya et al., 2019); silver ions yield high biocompatible that can be handled in biomedical settings without significant adverse effects (Vijayakumar et al., 2020).

Plant extracts frequently offer proper manipulation and control over crystal growth and stabilization. Nonetheless, using different plant extracts and reductants in the ENPs synthesis is challenging. Biosynthesis was performed to obtain ENPs with the desired shape, size, and dispersity, using plant extracts. It is a more straightforward method and is used in many therapeutic applications. Some plants, such as alfalfa, aloe vera leaves, Azadirachta indica (neem) leaves, Camellia sinensis, Capsicum annuum L., Cinnamomum camphora leaves, Datura metel, Emblica officinalis fruit, Ocimum sanctum, and geranium leaves, have been employed in the ENPs biosynthesis (Srivastava \& Choubey, 2019).

\subsection{Harnessing and Primary Uses of Engineering Nanomaterials for Commercial Mass Production}

ENMs have been used in cutting-edge technologies such as high-tech electronic devices, advanced chemical processes, or specialized medical treatments. However, these ENMs and their commercial applications could be bought in a popular supermarket into products used in daily life by an ordinary citizen. Therefore, nanoscience and nanotechnology are standard components of thousands of products that people use every day.

$\mathrm{TiO}_{2}$-ENM have been used in a dye-sensitized solar cell, synergetic degradation of antibiotics, photocatalytic hydrogen production, adsorption of organic pollutants, photocatalytic degradation of pharmaceutical and personal care products, $\mathrm{CO}_{2}$ photoreduction, sensor for the detection of organic compounds or gases, photocatalytic degradation of gaseous compounds, photocatalytic removal of organic and inorganic pollutants, high-performance electrode for supercapacitors, anode material for high rate lithium-ion batteries, degradation of organic dye molecules, photoreduction of heavy metals (HMs), photocatalytic activity for $E$. coli disinfection and biological pollutant degradation, highly efficient artificial photosynthesis, artificial $\mathrm{N}$-fixation, photocatalytic water splitting, photothermal therapy, photocatalytic water disinfection, solar water evaporation, antibacterial applications, renewable energy applications, ultrafast rechargeable lithium-ion batteries, high power sodium-ion anodes, membrane distillation, paints, medical implants, medical devices, cosmetics, food packaging, control of crop pathogens in agriculture, and nanofertilizer, among others.

Ag-ENMs are useful for photocatalytic decomposition/reduction of dyes, energy-saving windows, conductive inks for wearable electronics, supercapacitor in wearable energy devices, polymer solar cells, satisfactory thermal conductivity, and high thermal stability, antibacterial activity, edible coating, wearable, and implantable bioelectronics, electrocatalytic $\mathrm{N}_{2}$ fixation to $\mathrm{NH}_{3}$ under ambient conditions, electrochemical sensors, an electrocatalyst for the hydrogen evolution reaction, $\mathrm{CO}_{2}$ reduction to $\mathrm{CO}$, methanol or $\mathrm{CH}_{4}$, ammonia gas sensor, MCF-7 breast cancer cells imaging, plant nutrition, crop protection, and food packaging, among others.

$\mathrm{Zn}$-ENMs are used in crop production, bifunctional electrocatalysis, rechargeable batteries, highperformance supercapacitor electrodes, generation of hydrogen fuel in acid medium, photocatalytic reduction of $\mathrm{CO}_{2}$ into renewable hydrocarbon fuel, Zn-Air batteries, organic thin-film solar cell, water splitting, adsorbent of pollutants, removal of dyes, bio-medical applications, kidney cancer therapy, and antibacterial medicine, among others. Si-ENMs are used in high-performance anodes for lithium-ion batteries, biomedicine, food pathogen detection, crop production, quantitative detection of pesticides, suppression of plant diseases, and multichip packaging, among others. Fe-ENMs are used in photocatalytic degradation of bisphenol, intelligent packaging film, 
radiosensitizing medicine, medical nanofabrication, magnetic hyperthermia, magnetic resonance imaging in the innovative drug delivery, diagnosis, treatment, and therapy of tumor and cancer diseases, degradation of dyes, groundwater treatment, remediation of drinking water, elimination of environmental pollutants such as HMs, hydrocarbons or organic compounds, magnetic adsorptive-remediation of HMs, crop production, nutrient of crops, control of pest and diseases, and thin films for identification of pathogens, among others.

Al-ENMs applications are used in wound infection and drug-resistant clinical pathogens, removal of bacterial pathogens from wastewater, adsorption of organophosphate pesticides, removal of organic or pharmaceutical pollutants, degradation of dyes, detection of pollutant gases, and controlled release of plant growth regulators, among others. Ce-ENMs are used in photodecomposition and adsorption of hazardous organic pollutants, pesticide adsorption, crop nutrition, cosmetic packaging, and photocatalytic activity for antibiotic removal, among others. CNT-ENMs are used in selective photocatalytic $\mathrm{CO}_{2}$ reduction via dry reforming of methane to fuels, hydrogen evolution reaction, versatile energy storage, hybrid energy storage device, medical applications, ecofriendly and reusable catalyst, removal of organic pollutants, HMs removal, biosensors, selective chemical sensors, electrochemical detection of HMs, antimicrobial agent, nanoagriculture, green carrier material for pesticides controlled release, membrane for separation and inactivation pathogens, electrochemical immunosensor for multiplexed detection of food-borne pathogens, food packaging, determination of trace pollutants in food, and drug controlled release, among others.

\subsection{Ecological Drawbacks}

The high production volume, growing number of industries competing in nanotechnology, and increasing use of ENMs make their ecological risk a concern worldwide. Consequently, there is a prominent concern about ENMs because they have the potential for adverse effects after they are spread, but their release pathways, fate, and toxicity are not yet well known. The detrimental influences of graphene-related materials on soil-plant organisms from a terrestrial ecosystem were summarized by Yang et al. (2020), taking into account the perspectives of physiology, biochemistry, and gene expression. Besides, the risk to the aquatic ecology of $\mathrm{Al}_{2} \mathrm{O}_{3}$-ENPs with two crystalline phases (alpha- $\mathrm{Al}_{2} \mathrm{O}_{3}$ and eta- $\mathrm{Al}_{2} \mathrm{O}_{3}$ ) was studied by Nogueira et al. (2020). They verified the toxic potential of the ENPs toward Daphnia magna even in sublethal concentrations. Besides, the toxicity was associated with an increase in the reactive oxygen species (ROS) content and deregulation of antioxidant enzymatic/non-enzymatic. However, their results indicated that $\mathrm{Al}_{2} \mathrm{O}_{3}$ NPs stand for a minimal risk to organisms in surface waters. A study to utilize a small-scale rapid assay was designed to evaluate the fate and ecotoxicological impacts of copper-based ENPs $(\mathrm{Cu}$ and $\mathrm{CuO})$ in a diverse aquatic community (Wu et al., 2020a, b). They found higher uptake in D. magna and zebrafish (Danio rerio) than equivalent ionic exposures, suggesting that organisms took up Cu-based ENPs.

Similar studies have been carried out with soil and water microorganisms. The potential risk of shortterm exposure to environmentally realistic concentrations $(0.00,0.04,0.08$, and $0.12 \mathrm{ppm})$ of CuO-ENM on the ecological performance of a cosmopolitan freshwater fungus (Articulospora tetracladia) was studied for a short period (1, 2, 3, and 4 days) (Seena $\&$ Kumar, 2019). They stated that leaf litter decomposition and sporulation were affected by concentrations and exposure time of CuO-ENMs. It is well known for the complexity of evaluating the ecosystems because they contain hundreds of organisms that work together, and some of them are in the same food chain. Therefore, some considerations for improving the evaluation of the ecological hazards of ENMs were stated by Holden et al. (2016a, b), and they proposed three main recommendations. First, scientists should develop ecotoxicological tests with realistic exposure scenarios. Second, testing should proceed via tiers with iterative feedback that informs experiments with higher organisms. Finally, the ENM hazard assessments should involve greater coordination among ENM quantitative analysts, exposure modelers, and ecotoxicologists across government, industry, and academia (Holden et al., 2016a, b). Besides, the effects of ENMs on populations, communities, and ecosystems have been shown by Holden et al. (2016a, b), including transfer and accumulation of ENMs through food chains.

It has to be stated that ecological advantages regarding the use of ENMs have also been found. 
$\mathrm{SiO}_{2}$-ENMs were used as an additive to the corn oil methyl ester. The experimental results showed that the incorporation of ENMs had a positive effect on emission characteristics as ENMs act as an oxidation catalyst (Saravankumar et al., 2019). An ecological assessment of the photocatalytic degradation of 2,4-dinitrophenol (DNP) using a three-dimensional (3D) hybrid composite based on carbon nano-onionfunctionalized zinc-oxide tetrapods was performed via the germination of common gram seeds (Cicer arietinum L.) (Park et al., 2019). This study revealed the low toxicity and environmental safety of the synthesized hybrid 3D composites and their ability to decontaminate wastewater using photocatalytic technology. An additional advantage of ENMs was reported by Qian et al. (2018). They used soil amended with SWCNTs at concentrations of 3 and $10 \mathrm{ppm}$ to prove that ENMs change the microbial community composition, promote soil organic degradation, and improve soil fertility in a short time (Qian et al., 2018).

Nanoscience and nanotechnology have produced ENMs at commercial levels, which are now used in over 3000 products, as their functionalities and levels of complexity have been improved. ENMs are increasingly entering the environment with uncertain outcomes, including potential ecological effects. Therefore, there is a critical need to know the environmental, ecological, and health implications of ENMs. However, the current results are controversial in the ecological context because ENMs and species discussed above were quite different.

\subsection{The Collateral Effect of ENMs on Organisms}

We identified 1504 manuscripts from the Web of Science ${ }^{\circledR}$ database. However, there were only included 73 papers regarding plants, 58 about meso and macrofauna, and 51 regarding mycorrhizal fungi. In general, there is information on the effects of ENMs on plants and soil organisms that is controversial. Of selected articles that evaluated the effects of ENMs in plants, $43.83 \%$ reported positive effects, $34.24 \%$ negative, and $21.91 \%$ no effects. Regarding the impact on macrofauna and mesofauna, $20.68 \%$ reported no effect, while $79.31 \%$ reported adverse effects. ENMs on arbuscular mycorrhizal fungi and their association with plants had positive effects in $15.68 \%$ of studies.
However, $54.9 \%$ stated adverse effects and $29.41 \%$ no effects (Fig. 2). Therefore, the averages of the effects indicate that $23.62 \%$ of organisms improved their characteristics when they were spiked with ENMs, $54.39 \%$ were affected, and only $21.97 \%$ did not change any properties or characteristics spiked by ENMs. As for the experimental scenarios (laboratory, greenhouse, and field), for the select studies, mostly the investigations were carried out in laboratory conditions. The number of studies for each group evaluated is shown in Fig. 3. Besides, we found that studies regarding mycorrhizal fungi and meso and macrofauna were conducted on natural soil. However, the experiments were developed in agar and hydroponics medium for plants, mainly (Fig. 4).

\subsection{Effect of ENMs on Soil Microorganisms}

ENMs are rapidly integrated into industrial technologies, including agricultural production alternatives, such as nanofertilizers and pesticides. Being photocatalysts presents favorable oxidation reactions. The production and application of ENMs have high production figures and have been raised as an emerging and potential threat to natural ecosystems. Currently, the statistics for the concentration of these materials in the environment have been estimated. In Europe, the involuntary disposition of ENMs in soils through the application of sludge maintains a flow of 2380 $\mathrm{t}^{-1}$ of $\mathrm{TiO}_{2}$ (Sun et al., 2014). However, the actual levels of their concentration in soils are unknown with precision, both at local and global levels, but

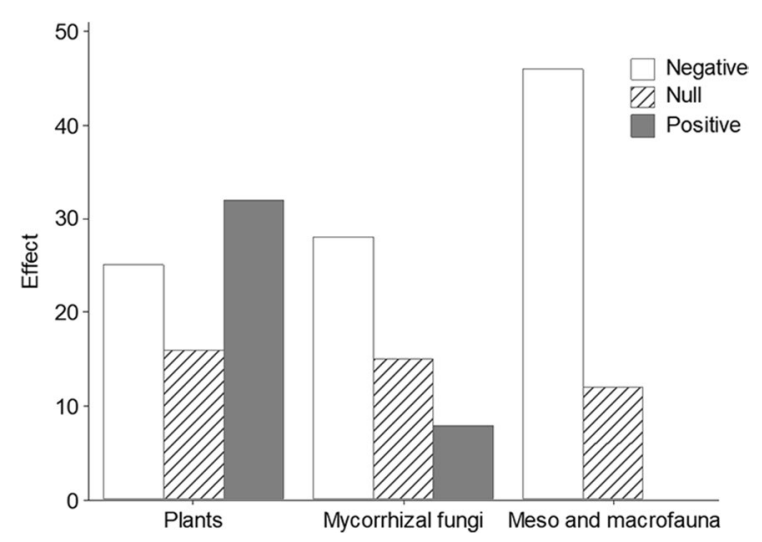

Fig. 2 Effects caused by ENMs on plants, meso and macrofauna, and mycorrhizal fungi 


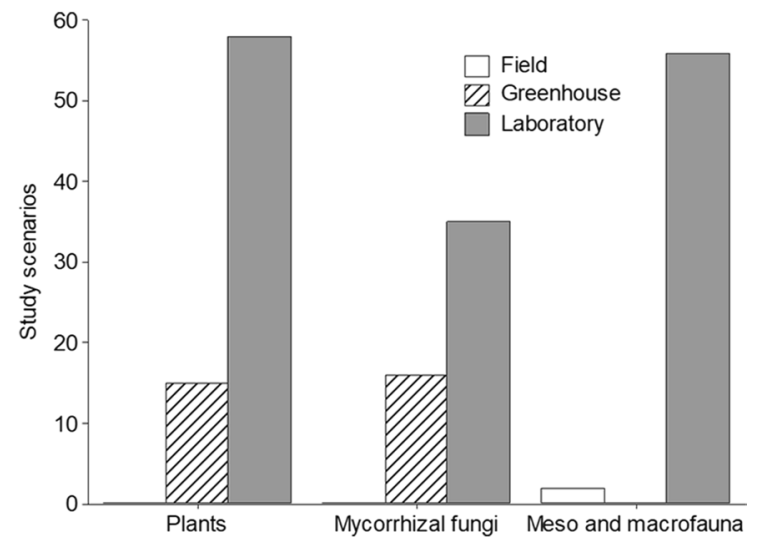

Fig. 3 Scenarios where the effects of ENMs on plants, meso and macrofauna, and mycorrhizal fungi were evaluated

concentrations are higher than water and air (Wang et al., 2016a, b).

When evaluating the effects of ENMs, microorganisms are considered biomarkers of soil quality. The biosecurity research of ENMs uses multivariate study strategies, from in vitro system evaluation to in vivo evaluation microcosms; it is the latter studies that direct the safe use of ENMs. Initially, evaluations of ENMs were carried out under artificial cultivation conditions, such as hydroponic issues or in inert artificial substrates, which ignored microbial responses in the soils of agroecosystems, the response criteria of the beneficial microorganisms due to the incidence of ENMs (Fig. 5) (Priester et al., 2012). It is crucial to consider the soil matrix in particles in each case, with its specific properties, scaling the study to counteract the data obtained from in vitro tests to microcosms. In the study of ENMs $\mathrm{Ag}$ and $\mathrm{Al}_{2} \mathrm{O}_{3}$ in Bacillus cereus and Pseudomonas stutzeri, using molecular methods, the results of the in vitro test revealed cytotoxic effects, which related to the increase in the genetic expression of the KatB gene; however, the results of the genetic transcription of the in vitro experiment did not match the results of the microcosm experiment (Fajardo et al., 2014). Similarly, the evaluation of $\mathrm{Fe}_{3} \mathrm{O}_{4}$-ENPs through enzymatic monitoring of E. coli reported a significant attenuation of the toxicity of ENPs in microcosms, contrary to what was observed in suspended cultures (Mahanty et al., 2019).

Within the evaluation conditions, exposure time plays an important role. Besides, metagenomic has been proven to be an essential contribution tool to identify the effects of ENMs in terms of microbial biodiversity in soil matrices, allowing the evaluation of genetic sequences and fragmentation of these using DNA and PCR extractions. The effect of $\mathrm{TiO}_{2}$-ENPs on the taxonomic composition and the functional profiles of the bacterial community of the soil matrix over time show the inhibition of taxa by $\mathrm{TiO}_{2}$-ENPs at a short-term exposure time (1 day) even in the low dose $\left(1 \mathrm{mg} \mathrm{kg}^{-1}\right)$. However, in the long term (60 days), these adverse effects at low concentration disappeared, reporting an increase in the abundance
Fig. 4 The number of studies in culture media where the effects of ENMs on plants, meso and macrofauna, and mycorrhizal fungi were evaluated

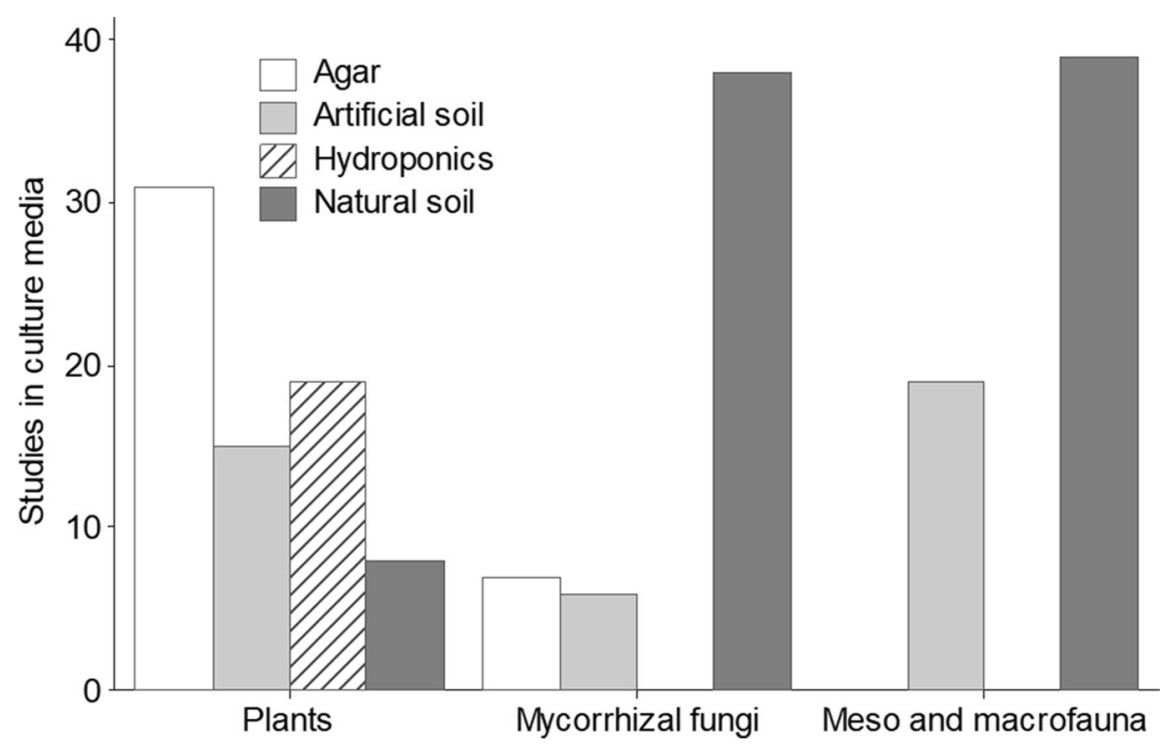


Fig. 5 Effects of engineered nanomaterials mostly evaluated in agricultural soils and the response of beneficiary microorganisms

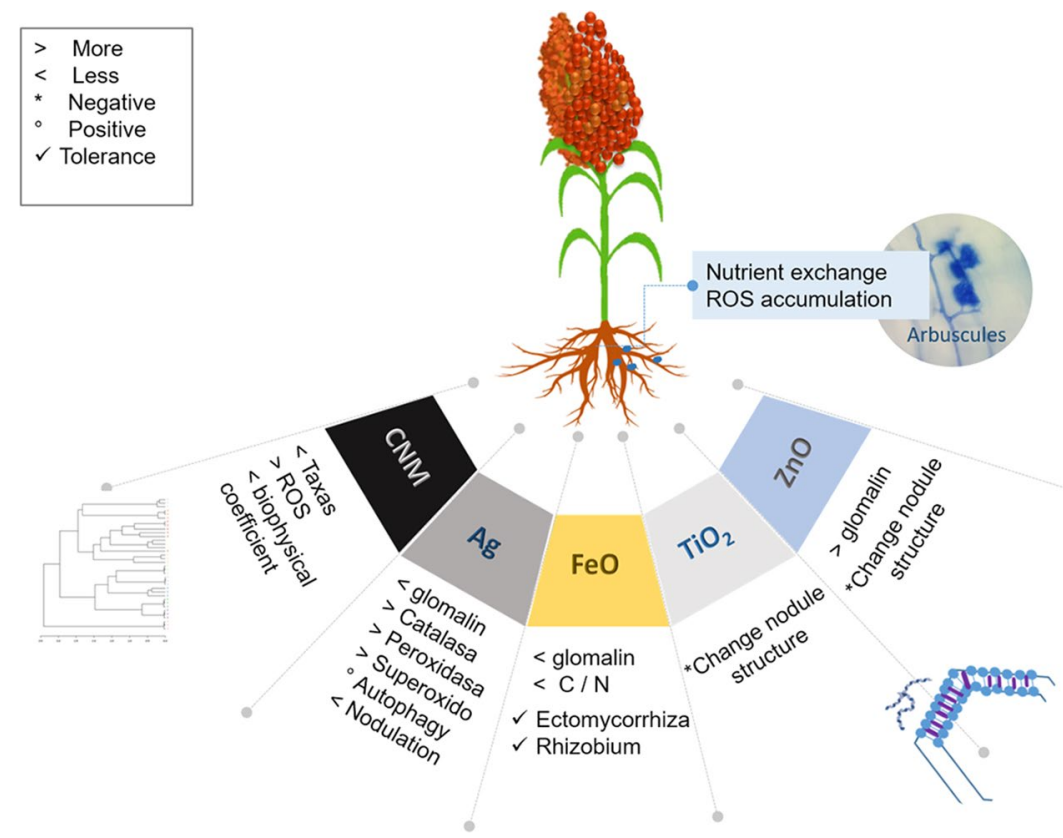

decomposition of recalcitrant organic pollutants $(\mathrm{Ge}$ et al., 2012).

The influence of $\mathrm{CeO}_{2}$-ENPs on soil quality is related to the loss of enzymatic activity (beta glucosidase and urease), which is reduced as the concentration of ENMs increases (Li et al., 2017). In terms of cellobiohydrolase $(\mathrm{CBH}), \beta-1,4-x y l o s i d a s e$ (XYL), $\quad \beta$-1,4-glucosidase (GLU), $\quad \beta-1,4-\mathrm{N}$ acetylglucosaminidase (AGA), and acid phosphatase (AP), the concentrations of AP, GLU, and AGA decrease in the presence of Ag-ENPs (100 mg kg-1) in soils amended with biosolids. Simultaneously, silver as bulk material $\left(\mathrm{Ag}^{+}\right)$caused the decrease of all enzymes in a correlated effect with the dose. It concluded that the dissolution factor of the ENPs reduces organic molecules' synthesis because only $37 \%$ of Ag-NP managed to dissolve after the end of the test time (Asadishad et al., 2018).

The effects of CNTs have been more related to the interruption of nutrient cycles in the soil by modifying the carbon and nitrogen cycle pathways ( $\mathrm{Wu}$ et al., 2020a, b). The biophysical coefficient (BQ), as an indicator of changes in organic matter in the soil, is interpreted as the amount of $\mathrm{CO}_{2}$ involved in the metabolism of respiration concerning the amount incorporated in the biomass. In soils spiked with SWCNT or MWCNT, the BQ has lower values in the presence of both materials, at a concentration 
of $1000 \mathrm{mg} \mathrm{kg}^{-1}$, compared to the levels reported by fullerene doses $\left(1,10,100\right.$, and $\left.1000 \mathrm{mg} \mathrm{kg}^{-1}\right)$ (Oyelami \& Semple, 2015). In terms of microbial biomass, the values are reduced even in doses below $500 \mu \mathrm{g} \mathrm{g}^{-1}$ MWCNT in soil with a high percentage of sand $(60.75 \%$ sand, $27.75 \%$ silt, and $7.50 \%$ clay) (Chung et al., 2011).

Oxidative stress is presumed as a critical mechanism of carbon ENMs in antibacterial applications. In graphene oxide (GO), the induced stress is lower in different species of Bacillus (Gurunathan, 2015). Besides, GO alters soil's microbial composition, but it does not fracture alpha diversity (Forstner et al., 2019). However, some authors consider that bulk materials, as positive controls, may incur false negatives since the bulk material has a solubility that ENMs do not reach, thus differing in terms of absorption and adsorption. It has also been considered that ENMs do not present complete bioavailability in the soil (Judy et al., 2015a, b).

Using humic acid as a suspending agent for ENMs could reduce the availability of free metal ions, reducing toxicity values. Regarding the bioavailability of Ag-ENPs, humic acids have reduced ligands to $\mathrm{Ag}^{+}$ ions capturing less $\mathrm{Ag}$ compared to the cysteine that dominates the absorption of Ag-ENPs, reducing its bioavailability (Luoma et al., 2016). The genetic study of the effect of Ag-ENPs applied in humic acid suspension showed the expression of genes classified in the category of extracellular sequestration of metal ions, as is the case of $\mathrm{OpgC}$. This protein takes possession of periplasmic glucans, achieving a negative charge potential for immobilization of metal ions (Meier et al., 2020). Within the modifications to the microbial community, the appearance of silver-tolerant bacteria is relevant. Before exposure concentrations within the range 49 to $287 \mathrm{mg} \mathrm{kg}^{-1}$, Rhodanobacter sp. was dominating $71 \%$ of the total bacterial population (Samarajeewa et al., 2017).

Similarly, Acidobacteria, Cyanobacteria, Bacteroidetes, and Nitrospirae have relative resistance to AgENMs, at doses with 10, 50, and $100 \mathrm{mg} \mathrm{kg}^{-1}$ (Yang et al., 2014). Electron microscopy techniques have shown how $\mathrm{Ag}^{+}$ions cause severe damage to the cell wall in the case of Nitrosomonas europaea, exhibiting the disintegration of nucleoids (Wang et al., 2017), when ENPs entered through the cell wall. Besides, Ag-ENMs accelerate cell death, promoting cell death and loss of bacterial species such as Bacillus megaterium and Bacillus thuringiensis. The release of $\mathrm{Ag}^{+}$ions due to the joint disposition of biosolids and Ag-ENPs is reported higher than in the particular case of the $\mathrm{AgNO}_{3}$ bulk material, with a difference of five times greater, ranging from 123 to $138 \mathrm{mg}$ of $\mathrm{Ag}$ $\mathrm{kg}^{-1}$ (Mirzajani et al., 2013).

In a load effect, the ENMs $\mathrm{TiO}_{2}$ and $\mathrm{Fe}_{3} \mathrm{O}_{4}$ were compared, both negative (-) and positive (+) charges, suggesting that the loading force is a function of context. Thus, $\mathrm{Fe}_{3} \mathrm{O}_{4}(-)$ decreased Rhizobium colonization compared to $\mathrm{Fe}_{3} \mathrm{O}_{4}(+)$ without this property, affecting the presence of arbuscular mycorrhizal fungi (AMF) communities at the root as reported by the multiple response permutation studies (MRPP) (Burke et al., 2015). Although the surface charge of the bacteria is affected by the ENMs depending on the $\mathrm{pH}$ of the study medium, extracellular polymeric substances (EPS) have been successfully evaluated in cellular protection against the toxicity of $\mathrm{CuO}$ - and $\mathrm{ZnO}-\mathrm{ENPs}$. Therefore, ionic chelators maintain an essential role in cellular response. In the case of CuO-ENPs, alkaline phosphatase values were lower in evaluating the bacterium Pseudomonas chlororaphis $\mathrm{O6}$, indicating minor damage to the outer membrane (Dimkpa et al., 2011a, b). In Pseudomonas chlororaphis O6, the EPS were polydispersed with a negative charge, which was neutralized by the effect of $\mathrm{Ag}$ ions and not by Ag-ENPs, since the zeta potential reported the ENMs charge as negative. As for the solubility of ENMs based on $10 \mathrm{mg} \mathrm{L}^{-1}$, the $\mathrm{pH}$ was an essential factor in the value of the concentration of Ag. At $\mathrm{pH}$ six, it decreased to $0.28 \mathrm{mg} \mathrm{L}^{-1}$, while at $\mathrm{pH}$ seven, the level detected was higher $\left(2.3 \mathrm{mg} \mathrm{L}^{-1}\right)$ (Dimkpa et al., 2011a, b).

In particles, the soil rhizosphere, the main nutrient storage area for crop production processes due to its dynamic interaction between roots and microorganisms, represents soil's functional biodiversity. Any change in the processes related to the nutrient cycle modifies the function and regulation of the ecosystem. In discussing the direct and indirect effects of ENMs on soil's microbial functional diversity, it has highlighted the role of plant growth-promoting microorganisms and those of symbiotic association, particularly bacteria of the genus Bacillus and Rhizobium, as well as AMF. These groups stand out for the degree of tolerance they present against different biotic and abiotic stress types. It is well known that ENMs generate reactive oxygen species (ROS) 
that potentiate oxidative stress, primarily damaging cellular structures (Zhang et al., 2011a, b). Quantitative proteomic analysis has allowed us to assess the expression of proteins involved in the detoxification of ROS. In Bacillus subtilis, the values increased in sebum exposures to $\mathrm{Mg}-\mathrm{ZnO}$-ENPs (Auger et al., 2019). For Bacillus thuringiensis, 34 possible sensitive proteins were identified, and the accumulation of envelope precursors, material involved in oxidative stress tolerance (Mirzajani et al., 2014). The absence of effects has been reported by the $\mathrm{TiO}_{2}$-ENPs (10, 100 , and $\left.1000 \mathrm{mg} \mathrm{kg}^{-1}\right), \mathrm{CeO}_{2}$-ENPs $\left(860 \mathrm{mg} \mathrm{kg}^{-1}\right.$ ), and MWCNT ( 3 and $300 \mathrm{mg} \mathrm{kg}^{-1}$ ), when indirectly assessing the activity of the AMF, utilizing the phosphorus content in red clover plants (Trifolium pratense var. Merula). There were no significant differences with the control; however, the percentages of fixed nitrogen were modified favorably, indicating high biological activity (Moll et al., 2016).

The AMF are forced biotrophs that can tolerate stress conditions and generate association with $80 \%$ of terrestrial plant species, including the main grain crops. In general terms, the AMF and plant association are characterized by the presence of extraradical hyphae, intraradical hyphae, arbuscules, vesicles, and spores of extraradical hyphae. By expanding in the rhizosphere, they contribute to the mobility of mineral nutrients such as $\mathrm{N}, \mathrm{P}, \mathrm{Cu}$, and $\mathrm{Zn}$. Arbuscles are structures of high activity in the exchange of nutrients that occur between symbionts. Their presence refers to the accumulation of ROS, such as hydrogen peroxide, while colonization, in particular, is related to enzymatic activities of antioxidant type (Wu et al., 2014). Cu-ENMs produce ROS by reacting with amines and carboxyl groups that make up the cell surface.

Moreover, beneficial fungi are not modified compared to bacterial communities (Parada et al., 2019). It implies that ENMs affect the ecology of bacteria but not of fungi. However, in general, research studies of the effects of ENMs on AMF symbiosis mention contradictory indices regarding the inhibition in the percentage of radical colonization. $\mathrm{TiO}_{2}$-ENPs were evaluated through the microbial composition analysis in Zea mays L. and Glycine max L. plants performing the DNA extraction method with PCR amplification (Table 1), in the direction of the $18 \mathrm{~S}$ rRNA region specific for AMF. It was shown that the presence of $\mathrm{TiO}_{2}$-ENPs $\left(200 \mathrm{mg} \mathrm{Kg}{ }^{-1}\right.$ ) generated a weak inhibition of the AMF communities, attributing the effect to the high concentration of Ti detected inside the roots (Burke et al., 2014). Contradictorily, the impact of $\mathrm{TiO}_{2}$-ENPs $\left(1,100\right.$, and $\left.1000 \mathrm{mg} \mathrm{kg}^{-1}\right)$ evaluated in wheat (Triticum ssp. Var. Fiorina), in a study aimed at the 16S rRNA region, reported 1295 operational taxonomic units, focusing on the edge Glomeromycota, without identifying the inhibitory effect of fungal diversity compared to the control treatment (Moll et al., 2017).

There exists one degree of interference in the symbiotic relationship because some toxins are expressed more sensitive to the effects of ENPs. For Glomus, the study targeting the 16S rRNA and 18S rRNA gene, high $\mathrm{Fe}_{3} \mathrm{O}_{4}$ concentrations exerted greater relative abundance in the Glomus genus and lower abundance in the case of Acaulosporaceae and Gigasporaceae. However, root colonization decreased, indicating that AMF and plant symbiosis was negatively affected (Cao et al., 2016). It follows that AMF operates detoxification strategies through intracellular compartmentalization mechanisms, by translocating excess metals to subcellular compartments and even to specific structures such as spores and vesicles, losing cell viability (Cornejo et al., 2013). Relief of heavy metal toxicity can be attributed to the effects of AMF mediated nutrition (Conversa et al., 2019).

There are a more significant number of studies (Table 1), confirming that AMF inoculation under ENMs exposure has a positive stimulus for plants. It implies that AMF is relieving nanotoxicity, reducing the bioavailability of metals, increasing the content of photosynthetic pigments and antioxidant capacity, and reducing ROS concentration. In the culture of Zea mays L., colonization by Glomus versiforme (Gv) and Glomus caledonium (Gc) was evaluated directly by the intersection method and indirectly by the root activity parameter with triphenyl tetrazolium chloride. At a high dose of ZnO-ENPs ( $800 \mathrm{mg} \mathrm{kg}^{-1}$ ), the colonization rate decreased, especially in the case of Gv. Moreover, it was found that AMF significantly alleviated the phytotoxicity induced by ZnO-ENPs by generating an increase in antioxidant activity, having some tolerance to stress by ZnO-ENPs (Wang et al., 2016a, b). Similarly, Funneliformis caledonium was studied in sweet sorghum (Sorghum bicolor L.), and AMF inoculation helped to reduce the adverse effects of synergistic toxicity of ZnO-ENPs (50, 250, and $500 \mathrm{mg} \mathrm{kg}^{-1}$ ) with cadmium (Wang et al., 2018a, b). 


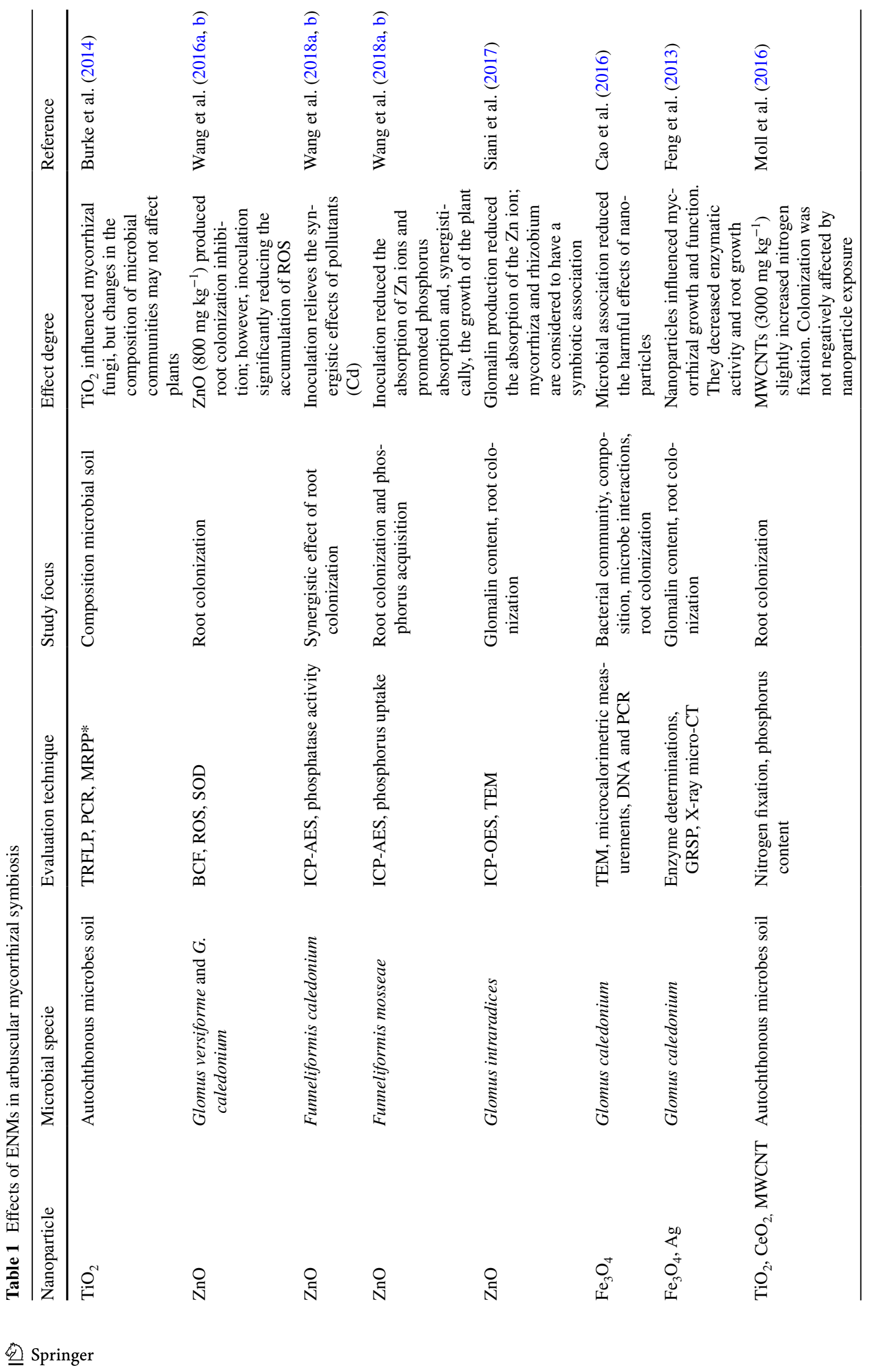


It is suggested that phytotoxicity relief is related to organic phosphorus. The inoculation of Funneliformis mosseae under different levels of organic phosphorus $\left(0,20\right.$, or $\left.50 \mathrm{mg} \mathrm{kg}^{-1}\right)$ showed that the effects were synergistic, keeping symbiosis stable in the presence of ZnO-ENPs (500 mg kg-1) (Wang et al., 2018a, b). More importantly, the promotion of metal chelators generated by the AMF symbiosis with the plant, such as glycoproteins, specifically glomalin, was attributed to the significant metal absorption reductions. The total glomalin production was studied by UV-Vis $595 \mathrm{~nm}$ spectrophotometry (Table 1), exposing the inoculation of Glomus intraradices to $\mathrm{ZnO}$-ENPs in the fenugreek culture (Trigonella foenum-graecum). The results showed that the glomalin content increased $15 \%$ in comparison with controls without inoculum exposed to $500 \mu \mathrm{g} \mathrm{g}^{-1}$ of $\mathrm{ZnO}$-ENPs (Siani et al., 2017). In contrast, the Ag-ENPs $\left(0.01 \mathrm{mg} \mathrm{kg}^{-1}\right)$ and $\mathrm{FeO}$-ENPs $\left(3.2 \mathrm{mg} \mathrm{kg}^{-1}\right)$ significantly reduced the production of glomalin in the symbiosis Glomus caledonium and clover (Trifolium repens); however, the rate of colonization increased according to the content of Ag-ENPs as well as the production of antioxidant enzymes such as catalase (CAT), peroxidase (POD), and superoxide dismutase (SOD) (Feng et al., 2013).

The ecological reduction of functions of AMFs has been observed when AMF is spiked with Ag-ENPs, through the characterization of alkaline phosphatase activity and the abundance of AMF-taxa. The diversity of AMF and the microbial community's composition was closely related to the content of dissolved organic carbon (DOC). It could be explained because Glomus increased as it is a genus that colonizes even through micellar fragments, contrary to the Acaulospora and Scutellospora genera that decreased at high concentrations of Ag-ENMs (Cao et al., 2017). Given the exposure of nanoscale zero-valent iron (nZV), AMF promotes apoplastic barriers in the radical apex, thus reducing ion translocation. Besides, AMF increased the protection against abiotic stress through the improved production of glomalin glycoprotein and cytokine and gibberellins in synergistic effect with inocula of rhizobacteria (Mokarram-Kashtiban et al., 2019). The above suggests that the toxic effects on microbes could be selective and depend on both the type of nanoparticles and the microbial communities' composition. 
In evaluation scenarios, where it is sought to have more significant similarity to the agricultural production scenarios, ENMs with coating design have been studied in conjunction with incorporating biosolids (sludge) to the soil, monitoring the properties of ENMs through aging. In evaluating the coatings with polyvinylpyrrolidone (PVP), it has been detected that Ag-ENPs with sulfurations affect the symbiotic plant-AMF interactions of importance for agricultural production systems, at concentrations of $1 \mathrm{mg} \mathrm{kg}^{-1}$. However, it is accused that bulk Ag ions cause more significant risk effects when incorporated into the soil employing biosolids (Judy et al., 2015a, b).

Ectomycorrhizal symbiosis is another type of mutualism that only occurs with $3 \%$ of terrestrial plant species; forest trees are potential hosts for this type of symbiont. Ectomycorrhizal fungi mediate responses to metal toxicity, water stress, and acidifying effects of the soil. When the impact of Ag-and Cu-ENPs on ectomycorrhizal colonization in English oak (Quercus robur L.) was evaluated, four ectomycorrhizal taxa were detected: Sphaerosporella brunnea, Thelephora terrestris, Paxillus involutus, and Laccaria proxima. In general terms, the foliar applications did not reduce the ectomycorrhizal infection. In concentrations of $25 \mathrm{ppm}$, both ENPs showed a higher degree of mycorrhization, being a value of $37.1 \%$ for $\mathrm{Cu}$ - and $37.5 \%$ in Ag-ENPs (Aleksandrowicz-Trzcinska et al., 2018). Another study reported that carbon and nitrogen concentrations were not affected concerning microbial biomass; moreover, the $\mathrm{C} / \mathrm{N}$ ectomycorrhizae ratio was directly affected by the increase in levels of $\mathrm{Fe}_{3} \mathrm{O}_{4}$ - and $\mathrm{SnO}_{2}$-ENPs (Antisari et al., 2013).

In the effects of $\mathrm{TiO}_{2}$-ENPs concerning Rhizobium leguminosarum, changes in cellular morphology have been detected in the nodules. It retards the processes of nitrogen fixation, suggesting an intervention in the response of the signals by the host (Fan et al., 2014). Similarly, exposure to ZnO-ENPs reports the change of cellular morphology toward round structures, affecting the onset of the nodulation and causing early senescence of the nodules (Huang et al., 2014). Ultra-high-resolution micrographs by scanning transmission electron microscopy (STEM) demonstrated the permanence of $\mathrm{CeO}_{2}$ and $\mathrm{ZnO}-\mathrm{ENPs}$ on the bacterial cell surface. $\mathrm{ZnO}-\mathrm{ENPs}$ were interned in the periplasmic space. Besides, the results of Fourier-transform infrared spectroscopy (FTIR) showed the change of extracellular polymeric substances before exposure to both materials (Bandyopadhyay et al., 2012). The surface charges of the ENMs were a factor that could influence the colonization of the radical systems by fixing bacteria (Burke et al., 2015). The nodulation inhibition is reported in treatment with $\mathrm{TiO}_{2^{-}}, \mathrm{ZnO}-$, and $\mathrm{Ag}$-ENPs to a greater extent than its bulk control.

In the same way, the genetic expression drops more than ten times in 239 plant genes, such as the Medicago truncatula. It is presumed that the biological pathways expressed are related to nitrogen metabolism, nodulation, heavy metal homeostasis, and abiotic stress response (Chen et al., 2015). Ag-ENPs at doses of $800 \mu \mathrm{g} \mathrm{kg}^{-1}$ decreased the nodulation, reducing nitrogen fixation activity by deteriorating cytoplasmic components in the induction of autophagy processes (Abd-Alla et al., 2016).

The analysis of operational taxonomic units (OTU) allowed reviewing the Rhizobium genus' taxonomic diversity, determining the value of species inhibited by ENMs, in exposure to $\mathrm{ZnO}$ - and $\mathrm{CeO}_{2}$-ENPs. The OTUs decreased in soils with cultivation contrary to those not planted, which suggests that plants accelerate the biogeochemical activity in the soil, promoting or limiting the effect of ENPs (Ge et al., 2014).

\subsection{Effect of ENMs on Plants}

Plants are organisms of significant environmental and nutritional importance; since, on the one hand, they manage to keep ecosystems in balance, also they promote critical biological processes such as the carbon cycle through the process of photosynthesis or as regulators of global climate change. On the other hand, these organisms, in addition to their importance in the environment, the function of satisfying the basic needs of humans and animals such as food since plants can obtain nutrients such as carbohydrates, fats, and essential proteins for its development (Fernando, 2012).

The release of ENMs is projected as a problem of environmental pollution due to crop production use. Crops are essential because they are the source of food and raw materials for almost $100 \%$ of people and more than $50 \%$ of industrial processes, respectively. However, most of the studies regarding the use of ENMs in agriculture have been carried out under controlled conditions, i.e., under greenhouse or plant-growth chamber conditions, during the first phenologic stages, i.e., they are only short-period studies. Besides, it has been reported that ENMs can 
be phytotoxic for several plant species, so that evaluations of different ENMs have been carried out at morphological, physiological, and biochemical levels, in different plant species (Rajput et al., 2018; Mansoor et al., 2019; Du et al., 2017). Therefore, studies at land conditions are necessary throughout the life cycle crops to understand the benefits or risks that ENMs could imply for ecosystems. It has to be stated that these studies have to be led by scientists and technologists with different specialties to analyze the problem from different approaches. Currently, the main ENMs are also used to test their effects on crops trying to get agricultural advantages from these developments.

\subsection{Effects of $\mathrm{TiO}_{2}$-ENPs on Plants}

The effects of $\mathrm{TiO}_{2}$-ENPs on crops depend mainly on the species of studied plants, the exposure time, and the concentration (Feizi et al., 2012). An experiment that used concentrations of 1,2,10, 100, and 500 ppm of $\mathrm{TiO}_{2}$-ENPs, using Triticum aestivum L., found that the germination rate was not affected by any of the concentrations; however, they could highlight that at the concentrations of 2 and $10 \mathrm{ppm}$, the elongation of roots and shoots was more significant in these treatments (Feizi et al., 2012). Another example where concentration dependence was evidenced was reported by Song et al. (2012). They found that concentrations lower than $200 \mathrm{mg} \mathrm{TiO}$-ENPs $\mathrm{L}^{-1}$ increased the length of the root of Lemna minor L. significantly; however, the root length decreased when the concentrations were 200,1000 , or $2000 \mathrm{mg}$ $\mathrm{L}^{-1}$. Likewise, it was observed that the chlorophyll content increased as the concentrations of these ENPs increased. Similarly, Morteza et al. (2013) found that the addition of 0.01 or $0.03 \%$ of $\mathrm{TiO}_{2}$-ENPs to Zea mays L. plants increased the carotenoid and chlorophyll a or b content.

However, Wu et al. (2017) found in their experiment with Oryza sativa L. a decrease in the biomass of the roots and leaves of plants exposed to concentrations of $\mathrm{TiO}_{2}$-ENPs of 100,250 , or $500 \mathrm{mg} \mathrm{L}^{-1}$, and also an increase was observed in antioxidant activity in response to stress produced by ENPs. Similarly, Boykov et al. (2014) reported that as $\mathrm{TiO}_{2}$-ENPs concentration increased, biomass production decreased while $\mathrm{TiO}_{2}$-ENPs negatively affected microRNA expressions.

\subsection{Effects of Iron Oxides-ENPs in Plants}

In general, iron oxide ENPs are considered biocompatible, biodegradable, and non-toxic ( $\mathrm{Hu}$ et al., 2018). Therefore, studies have been conducted where the impacts of these ENPs on seed germination, growth, and development have been evaluated and their absorption and translocation. In these studies, there has been evidence of favorable impacts depending on the concentration of iron oxide ENPs, as demonstrated by Tombuloglu et al. (2019). They observed that as the concentration increases to $500 \mathrm{mg} \mathrm{L}^{-1}$ of $\mathrm{Fe}_{3} \mathrm{O}_{4}$-ENPs, the Hordeum vulgare L. plant promoted the fresh weight of leaves and roots, translating into the increase in the growth of the plant. Besides, they also reported that $\mathrm{Fe}_{3} \mathrm{O}_{4}$-ENPs increased the content of chlorophyll, proteins, and the number of chloroplasts; likewise, $\mathrm{Hu}$ et al. (2018) found that at concentrations of 20 and $50 \mathrm{mg} \mathrm{L}{ }^{-1}$ of $\gamma-\mathrm{Fe}_{2} \mathrm{O}_{3}$-ENPs favored the germination of Citrullus lanatus (Thunb.) and Zea mays L. seeds, as well as root elongation in both cases. However, both studies (Hu et al., 2018; Tombuloglu et al., 2019) determined that with the increase in concentration (above 500 or $100 \mathrm{mg} \mathrm{L}^{-1}$, respectively), there was a decrease in antioxidant activity promoting oxidative stress.

On the other hand, evidence has been found that even at low doses, the effects may be concentrationdependent, as reported by Plaksenkova et al. (2019). They employed concentrations of 1,2 , and $4 \mathrm{mg} \mathrm{L}^{-1}$ of $\mathrm{Fe}_{3} \mathrm{O}_{4}$-ENPs. They found that at these doses, the rate of seed germination and elongation of the root of Eruca sativa Mill was significantly lower in experiments on germination, i.e., during a short-long test. However, when evaluating the effects of these concentrations in the hydroponic system, the length of the bud, root, and chlorophyll content increased, such as $\mathrm{Fe}_{3} \mathrm{O}_{4}$-ENPs concentration rise.

\subsection{Effects of $\mathrm{ZnO}$-ENPs on Plants}

ZnO-ENPs are considered the second most used ENPs since this can be utilized in many products for everyday use. Therefore, there is a more significant presence of $\mathrm{ZnO}$-ENPs in the environment, and accordingly, the concerns regarding potential environmental risks that these could generate have also increased (Balážová et al., 2018). For this reason, it is crucial to investigate the toxicity of this type of ENPs, 
mainly on primary producers such as plants that serve as a food source and leading intermediary in trophic chains (Djearamane et al., 2018).

For example, Lee et al. (2013) observed a decrease in biomass production and reduction of antioxidant activity in Fagopyrum esculentum Moench. Plants spiked with ZnO-ENPs at concentrations of 1 to $2000 \mathrm{mg} \mathrm{L}^{-1}$. Besides, plants bioaccumulated $\mathrm{Zn}$ in different tissues. Similarly, Balážová et al. (2018) found that the addition of 100 or $1000 \mathrm{mg} \mathrm{ZnO}$-ENPs $\mathrm{L}^{-1}$ decreased the bud and root length and harmed the development of secondary roots. However, despite the evidence of the adverse effects by ZnO-ENPs, other authors have reported the ENPs efficiency to grow crops. Because ZnO-ENPs are plant-growth promoters, they increase the amount of biomass produced and improve the antioxidant activity in Pisum sativum L., Cicer arietinum L., and Spirodela polyrhiza L. (Burman et al., 2013; Hu et al., 2013; Mukherjee et al., 2014).

\subsection{Effects of $\mathrm{CeO}_{2}$-ENPs on Plants}

Although $\mathrm{CeO}_{2}$-ENPs are among the ten nanomaterials with the highest production, there are few reports about their effects of these ENPs in higher plants (Rico et al., 2014; Zhang et al., 2011a, b). However, it is crucial to evaluate the $\mathrm{CeO}_{2}$-ENPs impacts on plants to obtain evidence regarding the ecological risks of these ENMs and the potential exposition toward the human being through the food chain. $\mathrm{CeO}_{2}$-ENPs can be absorbed from the root toward the shoots, and they can be distributed throughout the plant, as described by Zhang et al. (2011a, b) in the Cucumis sativus L. plant.

On the other hand, Rico et al. (2013) showed that Oryza sativa $\mathrm{L}$. treated with $\mathrm{CeO}_{2}$-ENPs presented cerium accumulation in the roots, more significant oxidative stress, and damage to the cell membrane of the roots. Wang et al. (2013) reported that the Solanum lycopersicum L. growth was smaller when plants were spiked with $\mathrm{CeO}_{2}$-ENPs, and, consequently, the biomass production decreased, but the ROS content in root was improved. In contrast, Xie et al. (2019) and Ma et al. (2018) found that the presence of $\mathrm{CeO}_{2}$-ENPs in Phaseolus vulgaris $\mathrm{L}$. and Brassica rapa L. plants, respectively, did not affect their growth, but in the case of Brassica rapa L., the chlorophyll content increased.

\subsection{Effects of $\mathrm{Al}_{2} \mathrm{O}_{3}$-ENPs on Plants}

Like other ENMs described above, it is not clear how is the interaction of destination and toxicity of $\mathrm{Al}_{2} \mathrm{O}_{3}$-ENPs released into the environment. However, despite the few studies, it has been made clear that they can induce abiotic stress-causing alterations during plant growth and development (Yanik \& Vardar, 2015). Examples of these alterations are the results obtained by Buklew et al. (2012), who observed that $\mathrm{Al}_{2} \mathrm{O}_{3}$-ENPs did not affect the seed germination stage of Nicotiana tabacum L. However, at the end of their experiment, they found little root development but also the reduction of biomass production, which coincides with the findings reported by Yanik \& Vardar, 2015) and Owjo et al. (2019), who also describe the decrease in root length and biomass production in Triticum aestivum L. plants spiked with $\mathrm{Al}_{2} \mathrm{O}_{3}$-ENPs at 5, 25, or $50 \mathrm{mg} \mathrm{mL}^{-1}$ and Trigonella foenum-graecum $\mathrm{L}$. at $100 \mu \mathrm{g} \mathrm{L}^{-1}$, respectively. Besides, the antioxidant activity also changed in both cases (Yanik \& Vardar, 2015; Owjo et al. 2019). These results are according to Yanik et al. (2015), who determined that $\mathrm{Al}_{2} \mathrm{O}_{3}$-ENPs increased the hydrogen peroxide content, but the catalase activity was reduced, causing oxidative stress in Triticum aestivum L. plants.

\subsection{Effects of $\mathrm{SiO}_{2}$-ENPs on Plants}

$\mathrm{SiO}_{2}$-ENPs have been widely used in plant nutrition and as an enhancer in plant growth and development as there is evidence of the increase in some morphological characteristics, as reported by Asgari et al. (2018). They evaluated the effects of $\mathrm{SiO}_{2}$-ENPs on the growth of Avena sativa $\mathrm{L}$. and observed that the presence of these ENMs improves the growth of this plant by producing more biomass in the shoots and roots. Besides, the concentration of proteins increased when the plants were spiked with $\mathrm{SiO}_{2}$-ENPs. Similarly, Mushinskiy et al. (2018) reported that $\mathrm{SiO}_{2}$-ENPs stimulated the length of roots and shoots, the chlorophyll, and carotenoid content and increased the production of Solanum tuberosum L. tubers.

However, although $\mathrm{SiO}_{2}$-ENPs promise good results in plant nutrition, it is necessary to continue evaluating the use of these ENMs on other plants, since results have been found where evidence is contrary to the above described, such as the case of what 
was reported by Karimi and Mohsenzadeh (2016). They discovered that Triticum aestivum L. plants amended with $\mathrm{SiO}_{2}$-ENPs decreased the biomass in roots and shoots but also chlorophyllic pigments (a and b) and carotenoids, while the lipid peroxidation was increased.

\subsection{Effects of Ag-ENPs on Plants}

Ag-ENPs are among the most studied ENMs about the properties and applications that they have in various areas of science and technology. More recently, Ag-ENPs were used in the agricultural sector, to stimulate the plant growth, control of pathogens and pests, or as accelerators and improvers in fruit ripening (Jasim et al., 2017; Yan \& Chen, 2019). According to them, Jasim et al. (2017) reported that Ag-ENPs increased the number of leaves, root elongation, and sprout length in Trigonella foenumgraecum L. plants. Besides, Salachna et al. (2019) found higher biomass production of leaves and bulbs Lilium sp. and the stimulation of flowering. A similar result was reported by Byczynska et al. (2019), who found that the Tulipa gesneriana L. plants showed early flowering, larger petals, producing higherquality flowers, as well as the increase in root length. In contrast, Rastrogi et al. (2019) found that the presence of these ENPs decreased the chlorophyll content and the root and shoot length of Triticum aestivum L. These controversial results witness the necessity of additional research regarding the use of Ag-ENPs and highlight that the delivery of Ag-ENPs or ENMs to the ecosystems must be regulated.

\subsection{Effects of CNTs on Plants}

According to existing reports regarding the effects of CNTs on plants, it has been found that their impact can be both positive and negative, so, according to this evidence, the use of these ENMs cannot yet be extensive in agricultural production. Tripathi et al. (2011), González-García et al. (2019), and Joshi et al. (2018) revealed that the use of CNTs increases the growth rate of plants, improving the fresh and dry weight of biomass, antioxidant activity, seed germination, and nutrient absorption in Cicer arietinum L., Solanum lycopersicum L., and Triticum aestivum L., respectively. On the contrary, Begum et al. (2012) reported that Lactuca sativa L., Amaranthus tricolor
L., Cucumis sativus L., and Oryza sativa L. are affected by the presence of CNTs, reducing the length of shoots and roots and increasing the wilting of the leaves. Besides, Begum et al. (2012) also reported that Glycine max L., Capsicum annuum L., and Abelmoschus esculentus (L.) Moench did not present toxic effects due to the presence of CNTs. Fan et al. (2018), Hamdi et al. (2015), and Cano et al. (2016) did not find effects of CNTS on the growth and development of Arabidopsis thaliana (L.) Heynh., Lactuca sativa L., and Zea mays L., respectively. These pieces of evidence are similar to other ENMs described above, in the sense that ENMs affect the growth and development of crops and the balance of ecosystems. These affectations are a function of the plant species, doses, or concentration of the ENMs, growth conditions, and of course the properties and characteristics of ENMs.

\subsection{Effect of ENMs on Mesofauna and Macrofauna of the Soil}

To date, ENMs have been used to study biological and ecological aspects, but these researches have been carried out in laboratory, greenhouse, and field conditions. These studies intended to know the toxicological ENMs effects on collembolas, isopods, and earthworms. These latter are the most used since they represented the most significant biomass number compared with the rest of the organisms classes that live in the soils (Edwards, 2004). Besides, earthworms participate in various vital functions such as the decomposition of organic matter, the nutrients cycle, and other components (Fragoso \& Rojas, 2014). Of the 58 selected studies showing the effects of ENMs on the mesofauna and macrofauna of the soil, $77.0 \%$ were performed with earthworms, followed by studies with isopods $(17.0 \%)$ and collembola $(6.0 \%)$. However, we found that most of this research was carried out under laboratory conditions (Fig. 3) and mainly in natural soil (Fig. 4). It has generated conflict and debate because it is not the same to evaluate and conclude from studies conducted on artificial soils, compared to natural land. After all, the soil matrix is involved with many factors that may influence organisms' toxicity (de Santiago-Martín et al., 2016). For instance, in the laboratory, no effects on mortality and reproduction were observed in E. fetida exposed to $1000 \mathrm{mg} \mathrm{TiO}$-ENPs kg-1 of the standard artificial OECD soil (Bouguerra et al., 
2016). However, some studies with artificial soil have reported that both low (14 to $50 \mathrm{mg} \mathrm{kg}^{-1}$ of Ag-ENPs) and high concentrations (> $1000 \mathrm{mg} \mathrm{kg}^{-1}$ of Ag NPs) have caused adverse effects on mortality and reproduction (Garcia-Velasco et al., 2016; Gomes et al., 2015; Bourdineaud et al., 2019). Nevertheless, in other studies with variates ENPs concentrations in natural soil was reported adverse effects in different parameters such as mortality reproduction, a decrease of carbohydrate, effect on CAT activity, and changes in the expression of genes in E. coli exposed to ENPs of $\mathrm{Zn}, \mathrm{CNTs}, \mathrm{Ag}$, and Ce (Świątek \& Bednarska, 2019; Xu et al., 2019; Hayashi et al., 2013; Novo et al. 2015; Lahive et al. 2017). These contradictory results suggested that the adverse effects depend on the type of organisms to be evaluated, methods of application of the NPs, doses, and soil's physical and chemical properties (Pérez-Hernández et al., 2020).

Despite the controversial cases associated with soil and physicochemical properties of ENMs, the above results can be worrisome in real scenarios, such as agricultural areas and forests. Indeed, Rajput et al. (2019) argued that once ENPs are released to the environment, they may be subject to bio/geo/transformation and consequently cause toxicity or changes in organisms' behavior. Therefore, it is crucial to generate studies in real scenarios to avoid contradictory conclusions without having performed experiments and known the effects on organisms and their interactions in agricultural lands and ecosystems (Kah et al., 2018). In this line, in a study under controlled conditions involving pumpkin and herbivorous plants, it was found that, when $\mathrm{CeO}_{2}$-ENPs were added to the soil, pumpkin plants had higher Ce content in stems, leaves, and roots compared to the control. Besides, when the grasshoppers were fed using pumpkin leaf tissue, high Ce contents were found compared to untreated grasshoppers. The finding showed that $\mathrm{CeO}_{2}$-ENPs accumulate in the leaf area and stems of pumpkin plants, and trophic transfer and possible contamination of the food chain occur (Hawthorne et al., 2014). In another study where Ce-ENPs were added (1000 $\mathrm{mg} \mathrm{kg}^{-1}$ dry soil) in soil pots containing lettuce (Lactuca sativa) and snails (Achatina fulica), a trophic transfer of Ce-ENPs from the plant toward the snails was demonstrated. It shows that the potential risk of transferring Ce to humans through the food chain is less obvious (Ma et al., 2018). By contrast, Chae et al. (2016) studied a trophic transfer of NPs from Saccharomyces cerevisiae yeast to Armadillidium vulgare through the Folsomia candida (collembola). Besides, it was shown that ENPs are transferred intact from yeast cells to insects. Therefore, the study demonstrated the transfer of ENPs through the terrestrial food chain and indicated the potential dangers of ENPs for organisms at different trophic levels. In this sense, it is essential to mention that not all organisms have the same capacity to respond to ENMs. In earthworms, under laboratory conditions, an avoidance behavior to Ag-ENMs and Zvi-ENPs was observed (Mariyadas et al., 2018; Liang et al., 2018). However, to the selected studies, the effects reported have been mostly adverse (Fig. 2).

On the other hand, due to terrestrial isopods' capacity to accumulate metals, they have been used for contaminants bioaccumulation studies (Godet et al., 2011). Studies have shown that $\mathrm{TiO}_{2}$ added to isopods' diet causes mortality and changes in enzymatic activity (Jemec et al., 2008). Other studies showed no effects on weight change and survival of Porcellio scaber after 14 days of feeding with diet contaminated with $\mathrm{TiO}_{2}$-ENPs under laboratory conditions (Novak et al., 2012). Curiously, in a field experiment, Jemec et al. (2016) did not find adverse effects in $P$. scaber when they were spiked with $\mathrm{TiO}_{2}$-ENPs. In this study, the organisms were

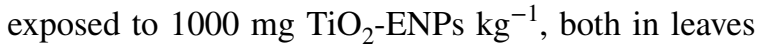
and soil contaminated. The results suggested that the organisms could detect metallic ions and therefore avoid their consumption. However, it is a concern that daily ENMs could be delivered to agricultural areas since farmers use river sediments and biosolids from wastewater treatment plants to improve the yields, and these biosolids could contain several ENPs (Chen et al., 2017). Besides, farmers could be using fertilizers that contain ENMs (Kim et al., 2017; Yuan, 2004). Therefore, plants and organisms that conform part of the human diet could be accumulating and transporting ENMs to the human food chain.

For all the above, it is possible that due to the contamination of agricultural and forestry areas caused by ENMs coming from urban or industrial regions, various soil beneficial organisms could be affected and the human food chain. Therefore, rigorous field studies that take into account the climate, soil types, cultivated plant species, and the properties of ENMs are required. These studies have to include ecological, environmental, and toxicological approaches. 


\subsection{Effect of ENMs on Human Beings Health}

Studying the effects on ENMs into the body is an important topic nowadays. However, it is challenging to reach a complete investigation on that because the entire context is multifactorial. Some factors could include the characteristics and properties of the ENMs, the environmental conditions, the body conditions (if the body is immunocompromised or if they are a susceptible group, mainly), or other factors that may have non-measurable effects. So, the research on these ENMs must go in a deep direction. On the order hand, we must remember that nature has produced nanomaterials before humans, but all organisms have evolved through millions of years along with these natural nanomaterials; therefore, the natural nanomaterials are not a risk for alive organisms.

According to Som et al. (2011), ENMs are expected to have the potential to be used as functionalized, improved, and novel products. These products could open the way for the use of ENMs in construction, medicine, automotive industry, and environmental and safety technology sectors; consequently, ENMs could become ubiquitous in industrial and consumer products in the future. Ecological and human health could be affected by the involuntary release of these products. For example, some ENMs unintentionally released from geotextiles will probably end up in the soil and then come into direct contact with humans and end up in wastewater.

Som et al. (2011) found that some ENMs could affect the environment less severely than human health, while others' case is vice versa, which is especially true for CNT. The assessment of environmental risks depends mostly on the respective product life cycles and the quantities of ENMs produced worldwide. Their study defined the criteria for human health: (i) acute toxicity, (ii) chronic toxicity, (iii) DNA deterioration, (iv) crossing and damage of tissue barriers, (v) brain damage, and translocation and effects of ENMs on the (vi) skin, (vii) gastrointestinal, or (viii) respiratory treatment.

In medicine, ENMs have potential applications as transporters and administrators of drugs and as carriers of these. Fadeel and Garcia-Bennett (2010) stated that many questions must be answered: What is the relationship between size, shape, and surface of the ENMs and their behavior in vivo? What is the fate of these when they fulfill their function? Are they degraded or metabolized, and are these products excreted by the body? Are there potential adverse effects of nanoparticles that can cause new unforeseen conditions such as accumulating chemicals? How could the impact of ENPs be measured and predicted? These answers must be solved for the future as soon as possible.

On the other hand, the advantages of ENMs as drug administrators are high stability, high loading capacity, incorporation of hydrophobic and hydrophilic substances, and compatibility in different forms of administration (oral, inhalation, etc.). The use of ENPs as carriers can also reduce the toxicity of drug incorporation. Furthermore, ENPs may or may not freely cross biological barriers indiscriminately, considering their specific physicochemical properties. ENMs are widely reported to cross tissue barriers and cause damage to the respiratory and gastrointestinal tract and the brain (Kendall \& Holgate, 2012). However, both in vivo and in vitro models have been developed to study their mechanisms. Still, they often do not correlate appropriately due to the different dosage regimens.

\subsection{Cytotoxicity Experiments}

There is an emerging field, nanotoxicogenomics, that attempts to correlate the profile of the global gene of expression of cells or tissues exposed to ENPs with biological or toxicological responses using cDNA microarray technologies, which can produce useful information (Fadeel \& Garcia-Bennett, 2010). Besides, other studies have correlated the effects of ENPs on cells and tissues with unpromising results.

\subsection{The Importance of the Dose, Structure, and Size of ENPs}

The ENMs size is a crucial characteristic that determines the effect of these on the organisms due to the surface/mass ratio that can substantially impact the chemistry of their surface. The dispersion state could be another factor to consider when the toxicity of specific ENMs is studied. $\mathrm{TiO}_{2}$-ENPs have been studied extensively, concluding that these materials' cytotoxicity is highly correlated to their mineralogical phase. Besides, it has been found that the toxicity of ENMs 
in the lungs is given by the surface reactivity, size, and surface area. Several studies have been conducted with Au-ENPs. Some of these studies suggest that the Au-ENPs size may influence cells' biological activity, suggesting that the Au-ENPs in drug delivery should not be seen merely as passive carriers. The above because Au-ENPs may play an active role in modulating biological and toxicological responses (Fadeel \& Garcia-Bennett, 2010).

\subsection{Cardiovascular Mechanisms}

According to Kendall and Holgate (2012), ENMs have cardiovascular effects by inhalation. It has led to a growing understanding of the nanosized materials' impact beyond the first point of contact with the lung. Epidemiological findings bind to atmospheric ENPs with cardiovascular diseases by a series of potential mechanisms, such as (i) atherogenesis enhanced by inflammation and destabilization of plaque in coronary and cerebral arteries, (ii) epithelial/endothelial interactions with ENPs that alter blood clotting status or fibrinolytic balance favoring thrombogenesis, (iii) ENPs or its soluble components that enter to the bloodstream to exert direct effects; and (iv) increase arrhythmia (Kendall \& Holgate, 2012).

In both humans and animal models, exposure to contaminants induces platelet activation and intravascular accumulation to promote blood clotting. Although different coagulation biomarkers were measured in many studies, the vehicle contaminant (especially PM2.5) was consistently associated with thrombosis. Studies on air pollution by particles opened the way with a series of studies showing ventricular and supraventricular arrhythmias linked to exposure to ENMs, especially in older people. Also, air pollution by particles is more linked to improved platelet activation in those at risk of coronary heart disease. Besides, a range of low toxicity ENPs has demonstrated in vitro platelet activation properties (Kendall \& Holgate, 2012). Most of the investigations of these studies have been carried out in vitro experiments so that these results could be misleading, and, therefore, standardized methodologies and collaboration between global health and environmental organisms must be reached to provide verification and validation of the experiments in vivo.
While we have documented environmental concerns and the damage that NMs cause to the environment, it is important to note that air pollution caused by microsized metals has been reported and discussed for many years. The report of Tidblad et al. (2012) recognize the contamination and corrosion of zinc, steel, and limestone during period of 22 years (1987-2009), according to tests carried out in at least 54 cities, including European countries and North America. However, in recent studies in the city of Athens, Greece, the data analyzed in the period 2003-2012, according to the report by Christodoulakis et al. (2017), indicate that the corrosion of materials such as zinc, carbon steel, limestone, and modern glass tends to decrease over the years, except for copper, since $\mathrm{O}_{3}$ is the parameter that affects the mass loss of copper and not in the rest of the materials. Therefore, in a rigorous comparison between the polluting effects between NMs and their bulk counterparts, it has been documented that NPs present in the air can cause a higher toxic effect due to properties such as size, shape, surface area, and surface load, among others. For example, Martinello et al. (2021) discussed the effects of the combustion of ceramics and the generation of NPs $(<10 \mathrm{~nm})$ and the effects on the health of workers, which with the COVID-19 pandemic can exacerbate respiratory diseases.

\subsection{Risks of Human Consumption Through the Food and Trophic Chain}

Potential benefits of the ENMs have been welcomed in the food industry, such as food packaging and food security, to deliver affordable and innocuous food to consumers. Notwithstanding, it has been demonstrated that ENMs pose a more significant threat to different organism species than bulk materials due to their physicochemical or biological properties. However, their potential risks to the consumers are not yet fully understood. Besides, there is a knowledge gap between the amounts of ENMs that could enter the human body through different foodstuffs. A review by Karimi et al. (2018) stated how the most widely found ENMs enter the human body, animals, and plants or are delivered to the environment, which could raise potential biosafety problems that review does not discuss human consumption of ENMs.

The possible risk of trophic transfer and transgenerational impact of ENMs were studied by Coman 
et al. (2019) in soybean plants. They discussed the effect of ENMs in terms of positive and negative impacts on growth, synthesis of metabolites, and the root-associated microorganisms. Moreover, they suggested a possible risk of trophic transfer and transgenerational effects of ENMs on soybean crops. These findings increase the evidence that clearly points up the collateral damage to the environment by ENMs. Therefore, comprehensive risk-assessment studies should be implemented before any industrial-scale production of ENM. Unfortunately, it is too late to say that, and the health of the consumers and environment could be in a latent risk.

ENMs are delivered into ecosystems with unknown implications in the human food chain. Besides, ENMs may accumulate in the fruits, grains, or edible sections of crops. However, they have damaging or advantageous effects on the agronomic traits modifying the nutritional value of crops with collateral effect within the trophic chain's different levels. The interaction of ENMs with microorganisms, vegetables, and animals and human cells has been the subject of diverse multidisciplinary research highlighting the toxicological aspects, but these studies seldom consider the human trophic chain by technical, ethical, and legal considerations. However, there is a fact that ENMs are into the human trophic chain because the uptake, translocation, and accumulation of these nanosized materials have been demonstrated in several studies regarding different foodstuffs such as edible crops, fruits, and fishes.

\section{Conclusions}

ENMs are multifunctional materials for various advanced applications. Several thousands of tons of these materials are synthesized by simple and high production rate manufacturing methods worldwide. These ENMs with outstanding properties never seen before are used in advanced devices or processes that improve the profits but commit human and environmental health.

ENMs such as $\mathrm{TiO}_{2}, \mathrm{Ag}, \mathrm{Zn}, \mathrm{Si}, \mathrm{Fe}, \mathrm{Al}, \mathrm{Ce}$, and CNT have been used in cutting-edge technologies such as synergetic photocatalytic degradation of antibiotics, hydrogen production, adsorption of organic pollutants, degradation of pharmaceutical and personal care products, $\mathrm{CO}_{2}$ photoreduction, sensors, artificial photosynthesis, artificial N-fixation, antibacterial applications, renewable energy applications, paints, medical implants, medical devices, cosmetics, food packaging, control of crop pathogens in agriculture, nanofertilizers, determination of trace pollutants in food, and drug controlled release, among others.

Currently, ENMs have attracted dramatically increasing interest in agriculture and food production because the possible environmental toxicity of ENMs could negatively influence edible crops and, therefore, human health. Interaction ENMs have been the subject of various multidisciplinary studies, but human or environmental health seldom has been the main objective. The ENMs risks regarding human consumption through the food and trophic chain have never been studied, but the results could be surprising and worrying.

Given the unavoidable involvement of ENMs in the agriculture sector and the current rather significant knowledge gaps, the use of ENMs should be judicious and only for specific applications to minimize their environmental release. There is a fact that ENMs are into the human trophic chain because the uptake, translocation, and accumulation of these nanosized materials have been demonstrated in different foodstuffs. Therefore, to shape sustainable nanotechnologies, the development of transdisciplinary teams conformed by scientists, technicians, politicians, business people, and entrepreneurs is urgent. We close by noting that several knowledge areas require further exploration to overcome current limitations for long-term experiments with higher plants or animals.

Acknowledgements Mexican authors thank the CONACYT.

Author Contribution H P-H, A P-M, CR S-C, S G-M, G M-P, F L-V, RG C-M, P J-K, and F F-L collected literature and wrote the manuscript. H P-H and F F-L designed, fine-tuned, and carried out the research idea. $\mathrm{H} \mathrm{P}-\mathrm{H}$ performed the statistical analysis. F F-L edited the manuscript. All authors read and approved the final manuscript.

Funding This research was funded by the Ciencia Básica SEP-CONACyT 287225, COAH-2019-C13-C006_FONCYTCOECYT, COAH-2021-C15-C095_FONCYT-COECYT, and Cinvestav Saltillo.

Availability of Data and Materials The datasets used and/ or analyzed during the current study are available from the corresponding author on reasonable request. 
Code Availability Not applicable.

\section{Declarations}

Ethics Approval Not applicable.

Consent to Participate Not applicable.

Consent for Publication Not applicable.

Competing Interests The authors declare no competing interests.

\section{References}

Abd-Alla, M. H., Nafady, N. A., \& Khalaf, D. M. (2016). Assessment of silver nanoparticles contamination on faba bean-Rhizobium leguminosarum bv. viciae-Glomus aggregatum symbiosis: Implications for induction of autophagy process in root nodule. Agriculture, Ecosystems \& Environment, 218, 163-177.

Aleksandrowicz-Trzcinska, M., Szaniawski, A., Studnicki, M., Bederska-Baszczyk, M., Olchowik, J., \& Urban, A. (2018). The effect of silver and copper nanoparticles on the growth and mycorrhizal colonisation of Scots pine (Pinus sylvestris L.) in a container nursery experiment. Iforest, 11, 690-697.

Antiohos, S., Papadakis, V., \& Tsimas, S. (2014). Rice husk ash (RHA) effectiveness in cement and concrete as a function of reactive silica and fineness. Cement and Concrete Research, 61(62), 20-27.

Antisari, L. V., Carbone, S., Gatti, A., Vianello, G., \& Nannipieri, P. (2013). Toxicity of metal oxide $\left(\mathrm{CeO}_{2}, \mathrm{Fe}_{34}\right.$, $\mathrm{SnO}_{2}$ ) engineered nanoparticles on soil microbial biomass and their distribution in soil. Soil Biology \& Biochemistry, 60, 87-94.

Asadishad, B., Chahal, S., Akbari, A., Cianciarelli, V., Azodi, M., Ghoshal, S., \& Tufenkji, N. (2018). Amendment of agricultural soil with metal nanoparticles: Effects on soil enzyme activity and microbial community composition. Environmental Science and Technology, 52, 1908-1918.

Asgari, F., Majd, A., Janoubi, P., \& Najafi, F. (2018). Effects of silicon nanoparticles on molecular, chemical, structural and ultrastructural characteristics of oat (Avena sativa $\mathrm{L}$ ). Plant Physiol Bioch, 127, 152-160.

Aubry, E., Liu, T., Perry, F., Mangin, S., Hauet, T., \& Billard, A. (2019). Synthesis of iron oxide films by reactive magnetron sputtering assisted by plasma emission monitoring. Materials Chemistry and Physics, 223, 360-365.

Auger, S., Henry, C., Pechaux, C., Lejal, N., Zanet, V., Nikolic, M. V., Manzano, M., \& Vidic, J. (2019). Exploring the impact of $\mathrm{Mg}$-doped $\mathrm{ZnO}$ nanoparticles on a model soil microorganism Bacillus subtilis. Ecotoxicology and Environmental Safety, 182: 109421
Balážová, L., Babula, P., Baláž, M., Bačkorová, M., Bujňáková, Z., Briančin, J., Kurmanbayeva, A., \& Sagi, M. (2018). Zinc oxide nanoparticles phytotoxicity on halophyte from genus Salicornia. Plant Physiology and Biochemistry, 130, 30-42.

Bandyopadhyay, S., Peralta-Videa, J. R., Plascencia-Villa, G., Jose-Yacaman, M., \& Gardea-Torresdey, J. L. (2012). Comparative toxicity assessment of $\mathrm{CeO}_{2}$ and $\mathrm{ZnO}$ nanoparticles towards Sinorhizobium meliloti, a symbiotic alfalfa associated bacterium: Use of advanced microscopic and spectroscopic techniques. Journal of Hazardous Materials, 24, 379-386.

Begum, P., Ikhtiari, R., Fugetsu, B., Matsuoka, M., Akasaka, T., \& Watari, F. (2012). Phytotoxicity of multi-walled carbon nanotubes assessed by selected plant species in the seedling stage. Applied Surface Science, 262, $120-124$.

Belgivayeva, A., \& Taniguchi, I. (2019). Synthesis and characterization of $\mathrm{SiO}_{2} / \mathrm{C}$ composite nanofibers as free-standing anode materials for Li-ion batteries. Electrochimica Acta., 328, 135101.

Bondarenko, O., Juganson, K., Ivask, A., Kasemets, K., Mortimer, M., \& Kahru, A. (2013). Toxicity of Ag, CuO and $\mathrm{ZnO}$ nanoparticles to selected environmentally relevant test organisms and mammalian cells in vitro: A critical review. Archives of Toxicology, 87(7), 1181-1200.

Bouguerra, S., Gavina, A., Ksibi, M., da Graça, R. M., RochaSantos, T., \& Pereira, R. (2016). Ecotoxicity of titanium silicon oxide $\left(\mathrm{TiSiO}_{4}\right)$ nanomaterial for terrestrial plants and soil invertebrate species. Ecotox Environ Safe, 129, 291-301.

Bourdineaud, J. P., Štambuk, A., Šrut, M., Radić Brkanac, S., Ivanković, D., Lisjak, D., Klobučar, R. S., Dragun, Z., Bačić, N., \& Klobučar. G. I. V. (2019). Gold and silver nanoparticles effects to the earthworm Eisenia fetida the importance of tissue over soil concentrations. Drug and Chemical Toxicology, 1-18

Boykov, I., Shuford, E., \& Zhang, B. (2014). Nanoparticle titanium dioxide affects the growth and microRNA expression of switchgrass (Panicum virgatum). Genomics, 14, $75-83$

Buklew, C., Ashlock, J., Winfrey, W., \& Zhang, B. (2012). Effects of aluminum oxide nanoparticles on the growth development, and micro $\mathrm{RNa}$ expression of tobacco (Nicotiana tabacum). PLoS ONE, 7, 34783.

Burke, D. J., Zhu, S., Pablico-Lansigan, M. P., Hewins, C. R., \& Samia, A. C. S. (2014). Titanium oxide nanoparticle effects on composition of soil microbial communities and plant performance. Biol Fert Soils, 50, 1169-1173.

Burke, D. J., Pietrasiak, N., Situ, S. F., Abenojar, E. C., Porche, M., Kraj, P., Lakliang, Y., \& Samia, A. C. S. (2015). Iron oxide and titanium dioxide nanoparticle effects on plant performance and root associated microbes. International Journal of Molecular Sciences, 16, 23630-23650.

Burman, U., Saini, M., \& Kumar, P. (2013). Effects of zinc oxide nanoparticles on growth and antioxidant system of chickpea seedlings. Toxicological and Environmental Chemistry, 95, 605-642.

Byczynska, A., Zawadzinska, A., \& Salachna, P. (2019). Silver nanoparticles preplant bulb soaking effects tulip production. Acta Agr Scand BSP, 69, 250-256. 
Cano, A., Kohl, K., Deleon, S., Payton, P., Irin, F., Saed, M., Shan, S., Green, M., \& Cañas-carrell, J. (2016). Determination of uptake, accumulation and stress effects in corn (Zea mays L.) growth in single-wall carbon nanotube contaminated soil. Chemosphere, 152, 117-122.

Cao, Y., \& Luo, Y. M. (2019). Pharmacological and toxicological aspects of carbon nanotubes (CNTs) to vascular system: A review. Toxicol Appl Pharmacol, 385, 114801.

Cao, J. L., Feng, Y. Z., Lin, X. G., \& Wang, J. H. (2016). Arbuscular mycorrhizal fungi alleviate the negative effects of iron oxide nanoparticles on bacterial community in rhizospheric soils. Front Env Sci, 4, 10.

Cao, J. L., Feng, Y. Z., He, S. Y., \& Lin, X. G. (2017). Silver nanoparticles deteriorate the mutual interaction between maize (Zea mays L.) and arbuscular mycorrhizal fungi: A soil microcosm study. Applied Soil Ecology, 119, 307-316.

Caramazana-González, P., Dunne, P., Gimeno-Fabra, M., Zilka, M., Ticha, M., Stieberova, B., Freiberg, F., McKechnie, J., \& Lester, E. (2017). Assessing the life cycle environmental impacts of titania nanoparticle production by continuous flow solvo/hydrothermal syntheses. Green Chemistry, 19, 1536-1547.

Chae, Y., Kim, S. W., \& An, Y. J. (2016). In vivo visual evaluation of nanoparticle transfer in a three-species terrestrial food chain. Chemosphere, 151, 101-107.

Charbgoo, F., Bin Ahmad, M., \& Darroudi, M. (2017). Cerium oxide nanoparticles: Green synthesis and biological applications. International Journal of Nanomedicine, 1401-1413

Chen, C., Unrine, J. M., Judy, J. D., Lewis, R. W., Guo, J., McNear, D. H., \& Tsyusko, O. V. (2015). Toxicogenomic responses of the model legume Medicago truncatula to aged biosolids containing a mixture of nanomaterials $\left(\mathrm{TiO}_{2}, \mathrm{Ag}\right.$, and $\left.\mathrm{ZnO}\right)$ from a pilot wastewater treatment plant. Environ Sci Tecnol, 49, 8759-8768.

Chen, C., Tsyusko, O. V., McNear, D. H., Judy, J., Lewis, R. W., \& Unrine, J. M. (2017). Effects of biosolids from a wastewater treatment plant receiving manufactured nanomaterials on Medicago truncatula and associated soil microbial communities at low nanomaterial concentrations. Science of the Total Environment, 609, 799-806.

Christodoulakis, J., Tzanis, C. G., Varotsos, C. A., Ferm, M., \& Tidblad, J. (2017). Impacts of air pollution and climate on materials in Athens, Greece. Atmospheric Chemistry and Physics, 17, 439-448.

Chung, S., \& Wang, C. (2012). Solution combustion synthesis of $\mathrm{TiO}_{2}$ and its use for fabrication of photoelectrode for dye-sensitized solar cell. Journal of Materials Science and Technology, 28(8), 713-722.

Chung, H., Son, Y., Yoon, T. K., Kim, S., \& Kim, W. (2011). The effect of multi-walled carbon nanotubes on soil microbial activity. Ecotoxicology and Environmental Safety, 74, 569-575.

Coman, V., Oprea, I., Leopold, L. F., Vodnar, D. C., \& Coman, C. (2019). Soybean interaction with engineered nanomaterials: A literature review of recent data. Nanomaterials, 9(9), 1248.

Conversa, G., Miedico, O., Chiaravalle, A. E., \& Elia, A. (2019). Heavy metal contents in green spears of asparagus (Asparagus officinalis L.) grown in Southern Italy: Variability among farms, genotypes and effect of soil mycorrhizal inoculation. Scientia Horticulturae, 256, 108559.

Cornejo, P., Perez-Tienda, J., Meier, S., Valderas, A., Borie, F., Azcon-Aguilar, C., \& Ferrol, N. (2013). Copper compartmentalization in spores as a survival strategy of arbuscular mycorrhizal fungi in Cu-polluted environments. Soil Biology \& Biochemistry, 57, 925-928.

de Santiago-Martín, A., Constantin, B., Guesdon, G., Kagambega, N., Raymond, S., \& Cloutier, R. G. (2016). Bioavailability of engineered nanoparticles in soil systems. J Hazard Toxic Radioact Waste., 20, B4015001.

De Volder, M., Tawfick, S., Baughman, R., \& Hart, A. (2013). Carbon nanotubes: Present and future commercial applications. Science, 339, 535-539.

Dimkpa, C. O., Calder, A., Britt, D. W., McLean, J. E., \& Anderson, A. J. (2011a). Responses of a soil bacterium, Pseudomonas chlororaphis O6 to commercial metal oxide nanoparticles compared with responses to metal ions. Environmental Pollution, 159, 1749-1756.

Dimkpa, C. O., Calder, A., Gajjar, P., Merugu, S., Huang, W. J., Britt, D. W., McLean, J. E., Johnson, W. P., \& Anderson, A. J. (2011b). Interaction of silver nanoparticles with an environmentally beneficial bacterium, Pseudomonas chlororaphis. Journal of Hazardous Materials, $88,428-435$.

Djearamane, S., Lim, Y., Wong, L., \& Lee, P. (2018). Cytotoxic effects of zinc oxide nanoparticles on cyanobacterium Spirulina (Arthrospira) platensis. PeerJ, 6, 4682.

Du, J., Wang, S. T., You, H., \& Zhao, X. S. (2013). Understanding the toxicity of carbon nanotubes in the environment is crucial to the control of nanomaterials in producing and processing and the assessment of health risk for human: A review. Environmental Toxicology and Pharmacology, 36(2), 451-462.

Du, W., Tan, W., Peralta-Videa, J., Gardea-Torresdey, J., Ji, R., Yin, Y., \& Guo, H. (2017). Interaction of metal oxide nanoparticles with higher terrestrial pants: Physiological and biochemical aspects. Plant Physiol Bioch, 110, 210-225.

Edwards, C. A. (2004) The importance of earthworms as key representatives of the soil fauna. In: Earthworm Ecology; Edwards, C.A., Ed.; CRC Press LLC: Boca Raton, FL, USA. pp. 3-11

Fadeel, B., \& Garcia-Bennett, A. E. (2010). Better safe than sorry: Understanding the toxicological properties of inorganic nanoparticles manufactured for biomedical applications. Advanced Drug Delivery Reviews, 62(3), 362-374.

Fajardo, C., Sacca, M. L., Costa, G., Nande, M., \& Martin, M. (2014). Impact of $\mathrm{Ag}$ and $\mathrm{Al}_{2} \mathrm{O}_{3}$ nanoparticles on soil organisms: In vitro and soil experiments. Science of the Total Environment, 473, 254-261.

Fan, R. M., Huang, Y. C., Grusak, M. A., Huang, C. P., \& Sherrier, D. J. (2014). Effects of nano-TiO 2 on the agronomically-relevant Rhizobium-legume symbiosis. Science of the Total Environment, 466, 503-512.

Fan, X., Xu, J., Lavoie, M., Peijnenburg, W., Zhu, Y., Lu, T., Fu, Z., Zhu, T., \& Quian, H. (2018). Multiwall carbon 
nanotubes modulate paraquat toxicity in Arabidopsis thaliana. Environmental Pollution, 233, 633-641.

Feizi, H., Moghaddam, P., Shahahmassebi, N., \& Fotovat, A. (2012). Impact of bulk and nanosized titanium dioxide $\left(\mathrm{TiO}_{2}\right)$ on wheat seed germination and seedling. Biol Trace Elem, 146, 101-106.

Feng, Y. Z., Cui, X. C., He, S. Y., Dong, G., Chen, M., Wang, J. H., \& Lin, X. G. (2013). The role of metal nanoparticles in influencing arbuscular mycorrhizal fungi effects on plant growth. Environmental Science and Technology, 47, 9496-9504.

Feng, P., Chang, H., Liu, X., Ye, S., Shu, X., \& Ran, Q. (2020). The significance of dispersion of nano- $\mathrm{SiO}_{2}$ on early age hydration of cement pastes. Materials \& Design, 186, 108320.

Fernández-Luqueño, F. (2019). Advantages and drawbacks of the nanotechnology and biotechnology toward shaping a global sustainable development. Biosci Biotech Res Asia, 16(4), 693-695.

Fernando, W. (2012). Plants: An international scientific open access journal to publish all facets of plants, their functions and interactions with the environment and other living organisms. Plants (basel)., 1, 1-5.

Forstner, C., Orton, T. G., Wang, P., Kopittke, P. M., \& Dennisa, P. G. (2019). Effects of carbon nanotubes and derivatives of graphene oxide on soil bacterial diversity. Science of the Total Environment, 682, 356-563.

Fragoso, C., \& Rojas, P. (2014). Biodiversidad de lombrices de tierra (Annelida: Oligochaeta: Crassiclitellata) en México. Rev Mex Biodivers, 85, 197-207.

Fu, L., Hamzeh, M., Dodard, S., Zhao, Y., \& Sunahara, G. (2015). Effects of $\mathrm{TiO}_{2}$ nanoparticles on ROS production and growth inhibition using freshwater green algae preexposed to UV irradiation. Environmental Toxicology and Pharmacology, 39(3), 1074-1080.

Garcia-Velasco, N., Gandariasbeitia, M., Irizar, A., \& Soto, M. (2016). Uptake route and resulting toxicity of silver nanoparticles in Eisenia fetida earthworm exposed through Standard OECD Tests. Ecotoxicology, 25(8), 1543-1555.

Ge, Y. G., Schimel, J. P., \& Holden, P. A. (2011). Evidence for negative effects of $\mathrm{TiO}_{2}$ and $\mathrm{ZnO}$ nanoparticles on soil bacterial communities. Environmental Science and Technology, 45, 1659-1664.

Ge, Y., Schimel, J. P., \& Holden, P. A. (2012). Identification of soil bacteria susceptible to $\mathrm{TiO} 2$ and $\mathrm{ZnO}$ nanoparticles. Applied and Environment Microbiology, 78, 6749-6758.

Ge, Y., Priester, J. H., Van de Werfhorst, L. C., Walker, S. L., Nisbet, R. M., An, Y. J., Schimel, J. P., Gardea-Torresdey, J. L., \& Holden, P. A. (2014). Soybean plants modify metal oxide nanoparticle effects on soil bacterial communities. Environmental Science and Technology, 48, 13489-13496.

Godet, J. P., Demuynck, S., Waterlot, C., Lemière, S., SoutyGrosset, C., Scheifler, R., Douay, F., Leprêtr, A., \& Pruvot, C. (2011). Growth and metal accumulation in Porcellio scaber exposed to poplar litter from $\mathrm{Cd}-, \mathrm{Pb}-$, and Zn-contaminated sites. Ecotoxicology and Environmental Safety, 74, 451-458.

Gomes, S. I. L., Hansen, D., Scott-Fordsmand, J. J., \& Amorim, M. J. B. (2015). Effects of silver nanoparticles to soil invertebrates: Oxidative stress biomarkers in Eisenia fetida. Environmental Pollution, 199, 49-55.

González-García, Y., López-Vargas, E., Cardenas-Pliego, G., Benavides-Mendoza, A., González-Morales, S., Robledo-Olivo, A., Alpuche-Solis, A., \& Júarez-Maldonado, A. (2019). Impact of carbon nanomaterials on the antioxidant system of tomato seedlings. International Journal of Molecular Sciences, 20, 5858.

Grubb, G., \& Bakshi, B. (2010). Life cycle of titanium dioxide nanoparticle production. Journal of Industrial Ecology, 15(1), 81-95.

Gurunathan, S. (2015). Cytotoxicity of graphene oxide nanoparticles on plant growth promoting rhizobacteria. Journal of Industrial and Engineering Chemistry, 32, 282-291.

Hamdi, H., de la Torre-Roche, R., Hawthorne, J., \& White, J. (2015). Impact of non-functionalized and aminofunctionalized multiwall carbon nanotubes on pesticide uptake by lettuce (Lactuca sativa L.). Nanotoxicology, 9, 172-180.

Hawthorne, J., De la Torre, R. R., Xing, B., Newman, L. A., Ma, X., Majumdar, S., \& White, J. C. (2014). Particlesize dependent accumulation and trophic transfer of cerium oxide through a terrestrial food chain. Environmental Science and Technology, 48(22), 13102-13109.

Hayashi, Y., Heckmann, L. H., Simonsen, V., \& Scott-Fordsmand, J. J. (2013). Time-course profiling of molecular stress responses to silver nanoparticles in the earthworm Eisenia fetida. Ecotoxicology and Environmental Safety, 98, 219-226.

Holden, P. A., Gardea-Torresdey, J. L., Klaessig, F., et al. (2016a). Considerations of environmentally relevant test conditions for improved evaluation of ecological hazards of engineered nanomaterials. Environmental Science and Technology, 50(12), 6124-6145.

Holden, P. A., Nisbet, R. M., Lenihan, H. S., Miller, R. J., Cherr, G. N., Schimel, J. P., \& Gardea-Torresdey, J. L. (2016b). Ecological nanotoxicology: Integrating nanomaterial hazard considerations across the subcellular, population, community, and ecosystems levels. Accounts Chem Res, 46(3), 813-822.

$\mathrm{Hu}, \mathrm{C}$. , Liu, Y., Li, X., \& Li, M. (2013). Biochemical responses of duckweed (Spirodela polyrhiza) to zinc oxide nanoparticles. Archives of Environmental Contamination and Toxicology, 64, 643-651.

Hu, J., Wu, C., Ren, H., Wang, Y., Li, J., \& Huang, J. (2018). Comparative analysis of physiological impact of $\gamma-\mathrm{Fe}_{2} \mathrm{O}_{3}$ nanoparticles on dicotyledon and monocotyledon. $J$ Nanosci Nanotechno, 18, 743-752.

Huang, Y. C., Fan, R., Grusak, M. A., Sherrier, J. D., \& Huang, C. P. (2014). Effects of nano- $\mathrm{ZnO}$ on the agronomically relevant Rhizobium-legume symbiosis. Science of the Total Environment, 497, 78-90.

Igbokwe, E., Daramola, M., \& Iyuke, S. (2019). Production of carbon nanotube yarns via floating catalyst chemical vapor deposition: Effect of synthesis temperature on electrical conductivity. Results in Phys, 15(102705), 1-7.

Ivask, A., Juganson, K., Bondarenko, O., Mortimer, M., Aruoja, V., Kasemets, K., Blinova, I., Heinlaan, M., Slaveykova, V., \& Kahru, A. (2014). Mechanisms of 
toxic action of $\mathrm{Ag}, \mathrm{ZnO}$ and $\mathrm{CuO}$ nanoparticles to selected ecotoxicological test organisms and mammalian cells in vitro: A comparative review. Nanotoxicology, 8 , 57-71.

Jasim, B., Thomas, R., Mathew, J., \& Radhakrishnan, E. (2017). Plant growth and diosgenin enhancement effect of silver nanoparticles in fenugreek (Trigonella foenumgraecum L.). Saudi Pharm J, 25, 443-447.

Jemec, A., Drobne, D., Remškar, M., Sepčić, K., \& Tišler, T. (2008). Effects of ingested nano-sized titanium dioxide on terrestrial isopods (Porcellio scaber). Environ Toxicol Chem, 27(9), 1904.

Jemec, A., Kos, M., Drobne, D., Koponen, I. K., Vukić, J., Ferreira, N. G. C., Loureiro, S., \& McShane, H. V. A. (2016). In field conditions, commercial pigment grade $\mathrm{TiO}_{2}$ was not harmful to terrestrial isopods but reduced leaf litter fragmentation. Science of the Total Environment, 571, 1128-1135.

Joshi, A., Kaur, S., Dharamvir, K., Nayyar, H., \& Verma, G. (2018). Multi-walled carbon nanotubes applied through seed-priming influence early germination, root hair, growth and yield of bread wheat (Tritucum aestivum L.). Journal of Science and Food Agriculture, 98, 3148-3160.

Josko, I., Oleszczuk, P., Dobrzynska, J., Futa, B., Joniec, J., \& Dobrowolski, R. (2019). Long-term effect of $\mathrm{ZnO}$ and $\mathrm{CuO}$ nanoparticles on soil microbial community in different types of soil. Geoderma, 352, 204-212.

Judy, J. D., Kirby, J. K., Creamer, C., McLaughlin, M. J., Fiebiger, C., Wright, C., Cavagnaro, T. R., \& Bertsch, P. M. (2015a). Effects of silver sulfide nanomaterials on mycorrhizal colonization of tomato plants and soil microbial communities in biosolid-amended soil. Environmental Pollution, 206, 256-263.

Judy, J. D., McNear, D. H., Chen, C., Lewis, R. W., Tsyusko, O. V., Bertsch, P. M., Rao, W., Stegemeier, J., Lowry, G. V., McGrath, S. P., Durenkamp, M., \& Unrine, J. M. (2015b). Nanomaterials in biosolids inhibit nodulation, shift microbial community composition, and result in increased metal uptake relative to bulk/dissolved metals. Environmental Science and Technology, 49, 8751-8758.

Kah, M., Kookana, R. S., Gogos, A., \& Bucheli, T. D. (2018). A critical evaluation of nanopesticides and nanofertilizers against their conventional analogues. Nat Nanotechnology, 13(8), 677-684.

Karimi, J., \& Mohsenzadeh, S. (2016). Effects of silicon oxide nanoparticles on growth and physiology of wheat seedlings. Rus J Plant Physl, 63, 119-123.

Karimi, M., Sadeghi, R., \& Kokini, J. (2018). Human exposure to nanoparticles through trophic transfer and the biosafety concerns that nanoparticle-contaminated foods pose to consumers. Trends in Food Science \& Technology, 75, 129-145.

Katal, R., Masudy-Panah, S., Tanhei, M., Farahani, M., \& Jiangyhong, H. (2020). A review on the synthesis of the various types of anatase $\mathrm{TiO}_{2}$ facets and their applications for photocatalysis. Chemical Engineering Journal, 384, 123384

Kendall, M., \& Holgate, S. (2012). Health impact and toxicological effects of nanomaterials in the lung. Respirology, 17(5), 743-758.
Kim, D. Y., Kadam, A., Shinde, S., Saratale, R. G., Patra, J., \& Ghodake, G. (2017). Recent developments in nanotechnology transforming the agricultural sector: A transition replete with opportunities. Journal of the Science of Food and Agriculture, 98(3), 849-864.

Kunhikrishnan, A., Shon, H., Bolan, N., El Saliby, I., \& Vigneswaran, S. (2015). Sources, distribution, environmental fate, and ecological effects of nanomaterials in wastewater streams. Critical Reviews in Environment Science and Technology, 45, 277-318.

Lahive, E., Matzke, M., Durenkamp, M., Lawlor, A. J., Thacker, S. A., Pereira, M. G., Spurgeon, D. J., Unrine, J. M., Svendsen, C., \& Lofts, S. (2017). Sewage sludge treated with metal nanomaterials inhibits earthworm reproduction more strongly than sludge treated with metal metals in bulk/salt forms. Environmental Science. Nano, 4(1), 78-88.

Lee, S., Kim, S., Kim, S., \& Lee, I. (2013). Assessment of phytotoxicity of $\mathrm{ZnO}$ NPs on a medicinal plant, Fagopyrum esculentum. Environmental Science and Pollution Research, 20, 848-854.

Li, K., \& Zhou, Z. (2019). Fabrication of FeOx-decorated on ethanol pretreated Ti grids for asymmetric supercapacitors. Journal of Nanoscience and Nanotechnology, 19, 4136-4141.

Li, B. T., Chen, Y. R., Liang, W. Z., Mu, L. L., Bridges, W. C., Jacobson, A. R., \& Darnault, C. J. G. (2017). Influence of cerium oxide nanoparticles on the soil enzyme activities in a soil-grass microcosm system. Geoderma, 299, $54-62$.

Liang, J., Xia, X., Yuan, L., Zhang, W., Lin, K., Zhou, B., \& $\mathrm{Hu}, \mathrm{S}$. (2018). The reproductive responses of earthworms (Eisenia fetida) exposed to nanoscale zero-valent iron (nZVI) in the presence of decabromodiphenyl ether (BDE209). Environmental Pollution, 237, 784-791.

Line, C., Camille, L. A., \& Flahaut, E. (2017). Carbon nanotubes: Impacts and behaviour in the terrestrial ecosystem - A review. Carbon, 123, 767-785.

Luoma, S. N., Stoiber, T., Croteau, M. N., Romer, I., Merrifeld, R., \& Lead, J. R. (2016). Effect of cysteine and humic acids on bioavailability of $\mathrm{Ag}$ from $\mathrm{Ag}$ nanoparticles to a freshwater snail. Nanoimpact, 2, 61-69.

Ma, H. B., Williams, P. L., \& Diamond, S. A. (2013). Ecotoxicity of manufactured $\mathrm{ZnO}$ nanoparticles - A review. Environmental Pollution, 172, 76-85.

Ma, X., Wang, Q., Rossi, L., \& Zhang, W. (2016). Cerium oxide nanoparticles and bulk cerium dioxide leading to different physiological and biochemical responses in Brassica rapa. Environmental Science and Technology, 50, 6793-6802.

Ma, Y., Yao, Y., Yang, J., He, X., Ding, Y., Zhang, P., Zhang, J., Wang, G., Xie, C., Luo, W., Zhang, J., Zheng, L., Chai, Z., Zhao, Y., \& Zhang, Z. (2018). Trophic transfer and transformation of $\mathrm{CeO}_{2}$ nanoparticles along a terrestrial food chain: Influence of exposure routes. Environmental Science and Technology, 52(14), 7921-7927.

Maboya, W., Coville, N., \& Mhlanga, D. S. (2019). One-step synthesis of carbon nanotubes with secondary growth of carbon nanofibers: Effect of chlorine, synthesis time and temperature. Materials Research Express, 6, 115016. 
Mahanty, B., Jesudas, S., \& Padmaprabha, A. (2019). Toxicity of surface functionalized iron oxide nanoparticles toward pure suspension culture and soil microcosm. Environ Nanotechnol Monit Manag, 12, 100235.

Manjunath, G., Pujari, S., Patil, D., \& Mandal, S. A. (2020). Scalable screen-printed high performance $\mathrm{ZnO}-\mathrm{UV}$ and Gas Sensor: Effect of solution combustion. Mater Sci Semicond Process, 107, 104828.

Mansoor, N., Younus, A., Jamil, Y., \& Shahid, M. (2019). Impact of nanosized and bulk $\mathrm{ZnO}$ on germination and early growth response of Triticum aestivum. Pak J Agri Sci, 56, 879-884.

Mariyadas, J., Amorim, M. J. B., Jensen, J., \& Scott-Fordsmand, J. J. (2018). Earthworm avoidance of silver nanomaterials over time. Environmental Pollution, 239, $751-756$.

Martinello, K., Hower, J. C., Pinto, D., Schnorr, C. E., Dotto, G. L., Oliveira, M. L. S., \& Ramos, C. G. (2021). Artisanal ceramic factories using wood combustion: A nanoparticles and human health study Geosci. Front, 12, 101151.

Medina-Pérez, G., Fernández-Luqueño, F., Vazquez-Nuñez, E., López-Valdez, F., Prieto-Mendez, J., Madariaga-Navarrete, A., \& Miranda-Arámbula, M. (2020). Remediation of polluted soils using nanotechnologies: Environmental benefits and risks. Polish Journal of Environmental Studies, 28(3), 1013-1030.

Meier, M. J., Dodge, A. E., Samarajeewa, A. D., \& Beaudette, L. A. (2020). Soil exposed to silver nanoparticles reveals significant changes in community structure and altered microbial transcriptional profiles. Environ Pollut, 258, 113816.

Miri, A., Darroudi, M., \& Sarani, M. (2019). Biosynthesis of cerium oxide nanoparticles and its cytotoxicity survey against colon cancer cell line. Applied Organometallic Chemistry, 34(1), 1-7.

Mirzajani, F., Askari, H., Hamzelou, S., Farzaneh, M., \& Ghassempour, A. (2013). Effect of silver nanoparticles on Oryza sativa L. and its rhizosphere bacteria. Ecotoxicology and Environmental Safety, 88, 48-54.

Mirzajani, F., Askari, H., Hamzelou, S., Schober, Y., Rompp, A., Ghassempour, A., \& Spengler, B. (2014). Proteomics study of silver nanoparticles toxicity on Bacillus thuringiensis. Ecotox Environ Safe, 100, 122-130.

Mokarram-Kashtiban, S., Hossein, S. M., Kouchaksaraei, M. T., \& Younesi, H. (2019). The impact of nanoparticles zero-valent iron (nZVI) and rhizosphere microorganisms on the phytoremediation ability of white willow and its response. Environ Sci Pollut R, 26, 10776-10789.

Moll, J., Gogos, A., Bucheli, T. D., Widmer, F., \& van der Heijden, M. G. A. (2016). Effect of nanoparticles on red clover and its symbiotic microorganisms. J Nanobiotechnology, 14,36 .

Moll, J., Klingenfuss, F., Widmer, F., Gogos, A., Bucheli, T. D., Hartmann, M., \& van der Heijden, M. G. A. (2017). Effects of titanium dioxide nanoparticles on soil microbial communities and wheat biomass. Soil Biology \& Biochemistry, 111, 85-93.

Morteza, E., Moaeveni, P., Farahani, H., \& Kiyani, M. (2013). Study of photosynthetic pigments changes of maize (Zea mays L.) under nano $\mathrm{TiO} 2$ spraying at various growth stages. Springerplus, 2, 247.

Mukherjee, A., Peralta-Videa, J., Bandyopadhyay, S., Rico, C., Zhao, L., \& Gardea-Torresdey, J. (2014). Physiological effects of nanoparticles $\mathrm{ZnO}$ in green peas (Pisum sativum L.) cultivated in soil. Metallomics, 6, 132-138.

Mushinskiy, A., Aminova, E., \& Korotkova, A. (2018). Evaluation of tolerance of tubers Solanum tuberosum to silica nanoparticles. Environmental Science and Pollution Research, 25, 34559-34569.

Nayar, P., Khanna, A., Kabiraj, D., Abhilash, S., Beake, B., Losset, Y., \& Chen, B. (2014). Structural, optical and mechanical properties of amorphous and crystalline alumina thin films. Thin Solid Films, 568, 19-24.

Nogueira, D. J., Vaz, V. P., Neto, O. S., da Silva, M. L. N., Simioni, C., Ouriques, L. C., Vicentini, D. S., \& Matias, W. G. (2020). Crystalline phase-dependent toxicity of aluminum oxide nanoparticles toward Daphnia magna and ecological risk assessment. Environ Res, 182, 108987.

Novak, S., Drobne, D., Valant, J., Pipan-Tkalec, Ž, Pelicon, P., Vavpetič, P., Nataša, G., Falnoga, I., Mazej, D., \& Remškar, M. (2012). Cell membrane integrity and internalization of ingested $\mathrm{TiO}_{2}$ nanoparticles by digestive gland cells of a terrestrial isopod. Environmental Toxicology and Chemistry, 31(5), 1083-1090.

Owjo, H., Hemmati, S., Heidari, R., \& Hakimzadeh, M. (2019). Effect of alumina $\left(\mathrm{Al}_{2} \mathrm{O}_{3}\right)$ nanoparticles and macroparticles on Trigonella foenum-graceum $\mathrm{L}$. in vitro cultures stress-related responses. 3 Biotech 9: 419

Oyelami, A. O., \& Semple, K. T. (2015). Impact of carbon nanomaterials on microbial activity in soil. Soil Biology \& Biochemistry, 86, 172-180.

Parada, J., Rubilar, O., Diez, M. C., Cea, M., da Silva, A. S., Rodriguez-Rodriguez, C. E., \& Tortella, G. R. (2019). Combined pollution of copper nanoparticles and atrazine in soil: Effects on dissipation of the pesticide and on microbiological community profiles. Journal of Hazardous Materials, 361, 228-236.

Park, S. J., Das, G. S., Schutt, F., Adelung, R., Mishra, Y. K., Tripathi, K. M., \& Kim, T. (2019). Visible-light photocatalysis by carbon-nano-onion-functionalized $\mathrm{ZnO}$ tetrapods: Degradation of 2,4-dinitrophenol and a plantmodel-based ecological assessment. NPG Asia Mater, 11,8 .

Pérez-Hernández, H., Fernández-Luqueño, F., Huerta-Lwanga, E., Mendoza-Vega, J., \& Álvarez-Solís, J. D. (2020). Effect of engineered nanoparticles on soil biota: Do they improve the soil quality and crop production or jeopardize them? Land Degrad Dev 1-18

Piccinno, F., Gottschalk, F., Seeger, S., \& Nowack, B. (2012). Industrial production quantities and uses of ten engineered nanomaterials in Europe and the world. Journal of Nanoparticle Research, 14(9), 1109.

Pine, T., Lu, X., Mumm, D., Samuelsen, G., \& Brouwer, J. (2007). Emission of pollutants from glycine-nitrate combustion synthesis processes. Journal of the American Ceramic Society, 90(12), 3735-3740.

Plaksenkova, I., Jermalonoka, M., Bankovska, L., Gavarane, I., Gerbreders, V., Sledevskis, E., Snikeris, J., \& Kokina, I. 
(2019) Effects of $\mathrm{Fe}_{3} \mathrm{O}_{4}$ nanoparticle stress on the growth and development of rocket Eruca sativa. J Nanomater 2678247

Priester, J. H., Ge, Y., Mielke, R. E., et al. (2012). Soybean susceptibility to manufactured nanomaterials with evidence for food quality and soil fertility interruption. PANAS, 109, 2451-2456.

Qian, H. F., Ke, M. J., Qu, Q., Li, X. X., Du, B. B., Lu, T., Sun, L. W., \& Pan, X. L. (2018). Ecological effects of singlewalled carbon nanotubes on soil microbial communities and soil fertility. Bulletin of Environment Contamination and Toxicology, 101(4), 536-542.

Rai, C., \& Haque, F. (2014). Synthesis of ultrafine $\mathrm{SiO}_{2}$ nanoparticles through ultrasonication-assisted sol-gel technique. J Adv Physics, 3, 1-4.

Rai, P., Kim, Y., Song, H., Song, M., \& Yu, Y. (2012). The role of gold catalyst on the sensing behavior of $\mathrm{ZnO}$ nanorods for $\mathrm{CO}$ and $\mathrm{NO}_{2}$ gases. Sensors Actuat B-Chemical, 165, 133-142.

Rajput, V., Minkina, T., Sushkova, S., et al. (2018). Effect of nanoparticles on crops and soil microbial communities. $J$ Soil Sediment, 18, 2179-2187.

Rajput, V., Minkina, T., Sushkova, S., Behal, A., Maksimov, A., Blicharska, E., Ghazaryan, K., Movsesyan, H., \& Barsova, N. (2019). $\mathrm{ZnO}$ and $\mathrm{CuO}$ nanoparticles: A threat to soil organisms, plants, and human health. Environ Geochem Hlth 1-12

Rastrogi, A., Zivcak, M., Tripathi, D., Yadav, S., Kalaji, H., \& Brestic, M. (2019). Phytotoxic effect of silver nanoparticles in Triticum aestivum: Improper regulation of photosystem I activity as the reason for oxidative damage in the clroroplast. Photosynthetica, 57, 209-216.

Reed, K., Cormack, A., Kulkarni, A., Mayton, M., Sayle, D., Klaessig, F., \& Stadler, B. (2014). Exploring the properties and applications of nanoceria: Is there still plenty of room at the bottom? Environmental Science. Nano, 1, 390-405.

Rico, C., Morales, M., McCreary, R., et al. (2013). Cerium oxide nanoparticles modify the antioxidative stress enzyme activities and macromolecule composition in rice seedlings. Environmental Science and Technology, 47, 14110-14118.

Salachna, P., Byczynska, A., Zawadzinska, A., Piechocki, R., \& Mizielinskra, M. (2019). Stimulatory effect of silver nanoparticles on the growth and flowering of potted oriental lilies. Agronomy, 9, 610.

Samarajeewa, A. D., Velicogna, J. R., Princz, J. I., Subasinghe, R. M., Scroggins, R. P., \& Beaudette, L. A. (2017). Effect of silver nano-particles on soil microbial growth, activity and community diversity in a sandy loam soil. Environmental Pollution, 220, 504-513.

Saravankumar, P. T., Suresh, V., Vijayan, V., \& Antony, A. G. (2019). Ecological effect of corn oil biofuel with $\mathrm{SiO} 2$ nano-additives. Energy Sources Part A-Recovery Util Environ Eff, 41(23), 2845-2852.

Seena, S., \& Kumar, S. (2019). Short-term exposure to low concentrations of copper oxide nanoparticles can negatively impact the ecological performance of a cosmopolitan freshwater fungus. Environ Sci-Process Impacts, 21(12), 2001-2007.
Shakeel, M., Jabeen, F., Shabbir, S., Asghar, M. S., Khan, M. S., \& Chaudhry, A. S. (2017). Toxicity of nano-titanium dioxide $\left(\mathrm{TiO}_{2}-\mathrm{NP}\right)$ through various routes of exposure: A review. Biological Trace Element Research, 172(1), $1-36$.

Shirai, T., Watanabe, H., Fuji, M., \& Takahashi, M. (2009). Structural properties and surface characteristics on aluminium oxide powders. Annual Report of Ceramic Engineering, 9, 23-31.

Siani, N. G., Fallah, S., Pokhrel, L. R., \& Rostamnejadi, A. (2017). Natural amelioration of Zinc oxide nanoparticle toxicity in fenugreek (Trigonella foenum-gracum) by arbuscular mycorrhizal (Glomus intraradices) secretion of glomalin. Plant Physiol Bioch, 112, 227-238.

Singh, I., Gupta, A., Dubey, S., Shafeeq, M., Banerjee, P., \& Sinha, A. (2016). Sol-gel synthesis of nanoparticles of gamma alumina and their application in defluoridation of water. Journal of Sol-Gel Science and Technology, 77, 416-422.

Som, C., Wick, P., Krug, H., \& Nowack, B. (2011). Environmental and health effects of nanomaterials in nanotextiles and façade coatings. Environment International, 37(6), 1131-1142.

Song, G., Gao, Y., Wu, H., Hou, W., Zhang, C., \& Ma, H. (2012). Physiological effect on anatase $\mathrm{TiO}_{2}$ nanoparticles on Lemna minor. Environmental Toxicology and Chemistry, 31, 2147-2152.

Srivastava, V., \& Choubey, A. (2019). Synthesis of nanostructured silver particles using Citrus limetta peel extract for catalytic degradation of azo dyes through electron relay effect. Adv Nat Sci-Nanosci Nanotechnol, 10, 1-8.

Stieberova, B., Zilka, M., Ticha, M., Freiberg, F., CaramazanaGonzález, P., McKechnie, J., \& Lester, E. (2019). Sustainability assessment of continuous-flow hydrothermal synthesis of nanomaterials in the context of other production technologies. Journal of Cleaner Production, 241, 1-10.

Sun, T. Y., Gottschalk, F., Hungerbühler, K., \& Nowack, B. (2014). Comprehensive probabilistic modelling of environmental emissions of engineered nanomaterials. Environmental Pollution, 185, 69-76.

Świątek, Z. M., \& Bednarska, A. J. (2019). Energy reserves and respiration rate in the earthworm Eisenia andrei after exposure to zinc in nanoparticle or ionic form. Environ Sci Pollut Res Int, 24933-24945

Tidblad J, Kucera V, Ferm M, Kreislova K, Brüggerhoff S.; Doytchinov S, Screpanti A, Grøntoft T, Yates T, Fuente, Daniel de la Fuente, Roots O, Lombardo T, Simon S, Faller M, Kwiatkowski L, Kobus J, Varotsos C, Tzanis C, Krage L, Schreiner M, Melcher M, Grancharov I, Karmanova N (2012) "Effects of air pollution on materials and cultural heritage: ICP Materials Celebrates 25 Years of Research", International Journal of Corrosion. 16.

Tombuloglu, H., Slimani, Y., Tombuloglu, G., Almessiere, M., \& Baykal, A. (2019). Uptake and translocation of magnetite $\left(\mathrm{Fe}_{3} \mathrm{O}_{4}\right)$ nanoparticles and its impact on photosynthetic genes in barley (Hordeum vulgare L.). Chemosphere, 226, 110-122. 
Tripathi, S., Sonkar, S., \& Sarkar, S. (2011). Growth stimulation of gram (Cicer arietinum) plan by water soluble carbon nanotubes. Nanoscale, 3, 1176-1181.

Vijayakumar, S., Malaikozhundan, B., Parthasarathy, A., Saravanakumar, K., Wang, M., \& Vaseeharan, B. (2020). Nano biomedical potential of biopolymer chitosancapped silver nanoparticles with special reference to antibacterial, antibiofilm, anticoagulant and wound dressing material. Journal of Cluster Science, 31, 355-366.

Vinogradov, V., Agafonov, A., Vinogradov, A., Gulyaeva, T., Drozdov, V., \& Likholobov, V. (2010). Sol-gel synthesis, characterization and catalytic activity of mesoporous $\gamma$-alumina prepared from boehmite sol by different methods. Journal of Sol-Gel Science and Technology, 56, 333-339.

Wang, X., \& Park, K. (2015). Analysis of compressive strength development of concrete containing high volume fly ash. Construction and Building Materials, 98, 810-819.

Wang, Q., Ebbs, S., Chen, Y., \& MA X, . (2013). Trans-generational impact of cerium oxide nanoparticles on tomato plants. Metallomics, 5, 753-759.

Wang, F. Y., Liu, X. Q., Shi, Z. Y., Tong, R. J., Adams, C. A., \& Shi, X. J. (2016a). Arbuscular mycorrhizae alleviate negative effects of zinc oxide nanoparticle and zinc accumulation in maize plants - A soil microcosm experiment. Chemosphere, 147, 88-97.

Wang, P., Menzies, N. W., Dennis, P. G., Guo, J. H., Forstner, C., Sekine, R., Lombi, E., Kappen, P., Bertsch, P. M., \& Kopittke, P. M. (2016b). Silver nanoparticles entering soils via the wastewater-sludge-soil pathway pose low risk to plants but elevated CI concentrations increase Ag bioavailability. Environmental Science and Technology, 20, 8274-8281.

Wang, J. A., Shu, K. H., Zhang, L., \& Si, Y. B. (2017). Effects of silver nanoparticles on soil microbial communities and bacterial nitrification in suburban vegetable soils. Pedosphere, 27, 482-490.

Wang, F. Y., Adams, C. A., Shi, Z. Y., \& Sun, Y. H. (2018a). Combined effects of $\mathrm{ZnO}$ NPs and $\mathrm{Cd}$ on sweet sorghum as influenced by an arbuscular mycorrhizal fungus. Chemosphere, 209, 421-429.

Wang, F. Y., Jing, X. X., Adams, C. A., Shi, Z. Y., \& Sun, Y. H. (2018b). Decreased $\mathrm{ZnO}$ nanoparticle phytotoxicity to maize by arbuscular mycorrhizal fungus and organic phosphorus. Environmental Science and Pollution Research, 25, 23736-23747.

Wu, B., Zhu, L., \& Chris-Li, X. (2017). Metabolomic analysis of $\mathrm{TiO}_{2}$ nanoparticles induced toxicological effects on rice (Oryza sativa L.). Environmental Pollution, 230, 302-310.

Wu, F., Harper, B. J., Crandon, L. E., \& Harper, S. L. (2020a). Assessment of $\mathrm{Cu}$ and $\mathrm{CuO}$ nanoparticle ecological responses using laboratory small-scale microcosms. Environ-Sci Nano, 7(1), 105-115.

Wu, F., You, Y., Werner, D., Jiao, S., Hu, J., Zhang, X., Wan, Y., Liu, J., Wang, B., \& Wang, X. (2020b). Carbon nanomaterials affect carbon cycle-related functions of the soil microbial community and the coupling of nutrient cycles. J Hazard Mater, 390, 122144.
Wu, Q., Zou, Y. N., Abd-Allah, E. F. (2014). Mycorrhizal association and ROS in plants. In: Ahmad, P. (Ed.), Oxidative Damage to Plants. Elsevier Inc. pp. 453-475

Xie, C., Ma, Y., Yang, J., Zhang, B., Luo, W., Feng, S., Zhang, J., Wang, G., He, X., \& Zhang, Z. (2019). Effects of foliar applications of ceria nanoparticles and $\mathrm{CeCl}_{3}$ on common bean (Phaseolus vulgaris). Environmental Pollution, 250, 530-536.

Xu, K., Liu, Y., Wang, X., \& Cheng, J. M. (2019). Effect of nano-carbon black surface modification on toxicity to earthworm (Eisenia fetida) using filter paper contact and avoidance test. Bulletin of Environment Contamination and Toxicology, 103, 206-211.

Yan, A., \& Chen, Z. (2019). Impacts of silver nanoparticles on plants: A focus on the phytotoxicity and underlying mechanism. International Journal of Molecular Sciences, 20, 1003.

Yang, Y., Quensen, J., Mathieu, J., Wang, Q., Wang, J., Li, M. Y., Tiedje, J. M., \& Alvarez, P. J. J. (2014). Pyrosequencing reveals higher impact of silver nanoparticles than $\mathrm{Ag}^{+}$on the microbial community structure of activated sludge. Water Research, 48, 317-325.

Yang, X., Chen, Y., Guo, F., Liu, X., Su, X., \& He, Q. (2020). Metagenomic analysis of the biotoxicity of titanium dioxide nanoparticles to microbial nitrogen transformation in constructed wetlands. J Hazard Mater, 384, 121376.

Yang, Y., Zhao, Y. Q., Wang, M. S., Meng, H. Q., \& Ye, Z. H. (2020). Mechanistic analysis of ecological effects of graphene nanomaterials on plant ecosystems. Asia-Pac J Chem Eng 2467

Yanik, F., \& Vardar, F. (2015). Toxic effects of aluminum oxide $\left(\mathrm{Al}_{2} \mathrm{O}_{3}\right)$ nanoparticles en root growth and development in Triticum aestivum. Water, Air, and Soil Pollution, 226, 296.

Yanik, F., \& Vardar, F. (2018). Oxidative stress response to aluminum oxide $\left(\mathrm{Al}_{2} \mathrm{O}_{3}\right)$ nanoparticles in Triticum aestivum. Biologia, 73, 129-135.

Yu, L., Guo, F., Liu, S., Yang, B., Jiang, Y., Qj, L., \& Fan, X. (2016). Both oxygen vacancies defects and porosity facilitated $\mathrm{NO}_{2}$ gas sensing response in $2 \mathrm{D} \mathrm{ZnO}$ nanowalls at room temperature. J Alloy Comod, 682, 352-356.

Yuan, G. (2004). Environmental nanomaterials: Occurrence, syntheses, characterization, health effect, and potential applications. Journal of Environmental Science and Health, Part A, 39(10), 2545-2548.

Zhai, Y., Huting, E. R., Liu, G., Baas, E., Peijnenburg, W. J. G. M., \& Vijver, M. G. (2019). Compositional alterations in soil bacterial communities exposed to $\mathrm{TiO}_{2}$ nanoparticles are not reflected in functional impacts. Environ Res, 178, 108713.

Zhang, H., He, X., Zhang, Z., Zhang, P., Li, Y., Ma, Y., Kuang, Y., Zhao, Y., \& Chai, Z. (2011a). Nano- $\mathrm{CeO}_{2}$ exhibits adverse effects at environmental relevant concentrations. Environmental Science and Technology, 45, 3725-3730.

Zhang, Z., He, X., Zhang, H., Ma, Y., Zhang, P., Ding, Y., \& Zhao, Y. (2011b). Uptake and distribution of ceria nanoparticles in cucumber plants. Metallomics, 3, 816-822. 
Zhang, P., Ma, Y., Zhang, Z., et al. (2012). Biotransformation of ceria nanoparticles in cucumber plants. ACS Nano, 6, 9943-9950.

Zhang, Q., Huang, J. Q., Qian, W. Z., Zhang, Y. Y., \& Wei, F. (2013). The road for nanomaterials industry: A review of carbon nanotube production, post-treatment, and bulk applications for composites and energy storage. Small (weinheim an Der Bergstrasse, Germany), 9(8), 1237-1265.
Zhu, L., \& Zeng, W. (2017). Room-temperature gas sensing of $\mathrm{ZnO}$-based gas sensor: A review. Sens Actuator A- Phys., 267, 242-261.

Publisher's Note Springer Nature remains neutral with regard to jurisdictional claims in published maps and institutional affiliations. 